\title{
Steric Crowding in Tetrel Bonds
}

\author{
Steve Scheiner* \\ Department of Chemistry and Biochemistry \\ Utah State University \\ Logan, UT 84322-0300
}

*email: steve.scheiner@usu.edu

phone: 435-797-7419

\begin{abstract}
The tetravalent character of tetrel atoms leaves only limited room for an incoming nucleophile to approach and engage in a noncovalent bond with a tetrel atom. Any such approach can only occur at the expense of internal geometric distortions. The balance between attractive forces and repulsive steric crowding was studied for a series of Lewis acids of the type $\mathrm{FTR}_{3}(\mathrm{~T}=\mathrm{Si}, \mathrm{Ge}, \mathrm{Sn}, \mathrm{Pb})$ which were allowed to interact with various bases. The strength and other properties of the tetrel bond are examined as the R groups are made progressively larger, varying from $\mathrm{H}$ and $\mathrm{CH}_{3}$ to isopropyl and t-butyl, which induce steric crowding with the incoming base. The effects of crowding which impede the bond can be offset by enlarging the $\mathrm{T}$ atom, by adding electronwithdrawing substituents to the Lewis acid, or by considering stronger bases such as anions. The tetrel bond energies reach up to $10 \mathrm{kcal} / \mathrm{mol}$ for a pair of neutral molecules with no electron-withdrawing substituents on the Lewis acid. Adding $-\mathrm{CF}_{3}$ substituents grows the interaction energy to as high as $35 \mathrm{kcal} / \mathrm{mol}$, and a further increment occurs for an anionic base, taking the maximum up to $54 \mathrm{kcal} / \mathrm{mol}$.
\end{abstract}




\section{INTRODUCTION}

Analogous to the venerable and thoroughly studied $\mathrm{H}$-bond ${ }^{1-3}$, it is now well accepted that the bridging proton can be replaced by any of a litany of larger atoms, without compromising the strength of the interaction 4-7. These substitute atoms are typically electronegative ones, drawn from the right side of the periodic table. Unlike the $\mathrm{H}$ atom which is partially positive within the context of a covalent $\mathrm{O}-\mathrm{H}$ or $\mathrm{N}-\mathrm{H}$ bond, the substitute atom's electronegativity leaves it with an overall partial negative charge, which would ordinarily tend to repel any incoming nucleophilic basic molecule. However, the negative charge around the substitute atom $\mathrm{X}$ is far from uniform, but is rather quite anisotropic. There is commonly a region of positive electrostatic potential, directly opposite the R-X covalent bond, which is surrounded by the expected negative areas. These positive regions are widely denoted as $\sigma$-holes, due to their origin and location, directly opposite the $\mathrm{R}-\mathrm{X} \sigma$-bond ${ }^{8-10}$. It is this $\sigma$-hole which can attract a nucleophile in their initial long range encounter. As the two molecules are drawn together, the interaction incorporates other attractive forces, most notably charge transfer and dispersion.

Depending on the identity of the atom replacing the bridging proton, and more particularly its familial nomenclature, these interactions are generally referred to as halogen, chalcogen, and pnicogen bonds. These noncovalent bonds have been intensively studied in the last years, leading to a number of general conclusions that are common to all ${ }^{11-28}$. In the first place, substituent effects markedly enhance the strength of the bond as electron-withdrawing substituents are placed on the electron-accepting Lewis acid molecule. As one moves down a column of the periodic table, e.g. $\mathrm{Cl} \rightarrow \mathrm{Br} \rightarrow \mathrm{I}$ the pertinent atom becomes both less electronegative and more polarizable, all factors which contribute to a stronger bond. There is a reluctance of first-row atoms $\mathrm{F}$, $\mathrm{O}$, and $\mathrm{N}$ to participate as electron acceptors in these bonds, although they can be persuaded to do so by, for example, adding strongly electron-withdrawing substituents, as in $\mathrm{NFH}_{2}$ which, unlike $\mathrm{NH}_{3}$, will engage in a pnicogen bond ${ }^{29}$.

These ideas have recently been extended one column to the left in the periodic table from the pnicogens, to include the tetrel family of atoms. Although the current moniker of a tetrel bond was coined fairly recently ${ }^{30}$, evidence of their presence goes back some years earlier. Early calculations ${ }^{31}$ documented the ability of both $\mathrm{SiH}_{4}$ and $\mathrm{SiF}_{4}$ to form such a bond with $\mathrm{NH}_{3}$, which was confirmed by rotational spectra ${ }^{32}$. Free-jet IR spectroscopy ${ }^{33}$ suggested that such a bond can form between $\mathrm{SiF}_{4}$ and either $\mathrm{N}_{2}$ or $\mathrm{CO}$, despite the weakness of the latter bases. The idea of a tetrel bond was also invoked in an experimental study ${ }^{34}$ of a reaction mechanism, which went on to suggest this bond becomes weaker as the size of the tetrel atom gets smaller, an idea that has been echoed since ${ }^{35-36}$. It is accepted ${ }^{37-38}$ that like the other related noncovalent bonds, the tetrel bond is also strengthened as more electron-withdrawing substituents are added to the Lewis acid ${ }^{39-40}$, as in the case of $\mathrm{SiF}_{4}$, or if the Lewis acid bears a positive charge ${ }^{41-42}$, or likewise in the case of an anionic base ${ }^{43}$. 
Tetrel bonds can appear within the intramolecular context of a single molecule ${ }^{44-47}$ as in 1-methylsilatrane ${ }^{48}$ or trifluorosilylhydrazines ${ }^{44}$. The concept has been broadened to include a variety of Lewis bases ${ }^{49}$, such as radicals ${ }^{50-51}$, anions ${ }^{43,52-53}$, carbenes ${ }^{54-55}$, or $\pi$-systems ${ }^{56-58}$. There are also indications that an incipient tetrel bond is a prime ingredient in the idea of $\mathrm{S}_{\mathrm{N}} 2$ chemical reactions ${ }^{6,36,53,59-60}$, or in biological processes ${ }^{61}$, and in the formation of metal-organic frameworks ${ }^{62-63}$. Tetrel bonds are not necessarily limited to $\sigma$-hole interactions where a nucleophile approaches directly opposite a covalent bond, but can also involve $\pi$-holes which lie out of the molecular plane ${ }^{64-65}$. The study of these interactions has proliferated quite a bit in the last few years ${ }^{40,66-70}$, which has included examination of the way tetrel bonds can be strengthened via cooperative effects ${ }^{71-72}$.

There is one essential factor concerning tetrel bonds which makes them rather different from their related noncovalent cousins. Taking the halogen bond as an example, the approaching nucleophile is separated by $180^{\circ}$ from the $\mathrm{R}$ group that is covalently attached to the halogen atom. Things get only a little more crowded for the chalcogen and pnicogen atoms. In the case that the $\mathrm{R}_{3} \mathrm{Z}$ molecule $(\mathrm{Z}=$ pnicogen) is trigonal pyramidal in shape, a nucleophile could still approach the central $\mathrm{Z}$ atom without incurring substantial steric repulsion with the R groups, separated from them by as much as $109^{\circ}$. But the situation becomes more crowded for tetrel atoms. With roughly tetrahedral spacing of its four substituents, a nucleophile would be separated from the $\mathrm{R}$ groups by only something on the order of $70^{\circ}$. In order to reduce the destabilizing effects of the associated steric repulsions, the Lewis acid would probably need to undergo a good deal of angular deformation, which would introduce its own energetic cost.

So the issue of steric crowding is a highly important one for tetrel bonds, but nonetheless one which has been scarcely studied. This issue is of special importance as tetrel bonds show evidence of being the strongest of the entire family of related noncovalent interactions ${ }^{73-75}$. It is the purpose of the current work to thoroughly analyze the effects that steric repulsions can have upon such bonds, and their ability to form at all. In an effort to do so, tetrel atoms $\mathrm{T}$ varying in size from $\mathrm{Si}$ to $\mathrm{Ge}, \mathrm{Sn}$, and $\mathrm{Pb}$ are considered as the central atom in FTR 3 Lewis acids, so as to consider how tetrel atom size relates to crowding effects. ( $\mathrm{C}$ was not considered as its tetrel bonds are quite weak.) Starting with $\mathrm{H}$ as the group attached to $\mathrm{T}$, this substituent is progressively enlarged to methyl, and thence to the bulkier isopropyl and t-butyl groups. The restriction to alkyl groups reduces any differences in electron-withdrawing power of the substituents, keeping the focus on purely steric factors. But at the same time, the ability of electron-withdrawing substituents to enhance the tetrel bond strength is considered, separately from steric effects, by comparing $\mathrm{CF}_{3}$ to $\mathrm{CH}_{3}$ as $\mathrm{R}$ groups, as well as considering halogen atoms of varying size and electron-withdrawing power as alternate substituents. The power of stronger nucleophiles to potentially overcome the inhibiting effects of possibly crippling steric crowding is evaluated by replacing the neutral $\mathrm{NH}_{3}$ base by various anions. 


\section{SYSTEMS AND METHODS}

The unsubstituted $\mathrm{TH}_{4}$ molecules $(\mathrm{T}=\mathrm{Si}, \mathrm{Ge}, \mathrm{Sn}, \mathrm{Pb}$ ) were each taken as a starting point Lewis acid; one $\mathrm{H}$ atom was replaced by $\mathrm{F}$ so as to provide a reasonably strong $\sigma$-hole opposite this $\mathrm{F}$ atom in $\mathrm{FTH}_{3}$, with which a base can interact. The possibility of steric crowding was introduced in stages, replacing each of the three $\mathrm{H}$ atoms first by $\mathrm{CH}_{3}$, and then by isopropyl and t-butyl. In order to consider the ability of electron-withdrawing substituents on the tetrel atom to overcome steric crowding, a number of $\mathrm{CF}_{3}$ groups were placed on the $\mathrm{T}$, as well as halogen atoms of varying size. $\mathrm{NH}_{3}$ was employed as the primary electron donor, due to its simplicity, containing a single lone pair and with no $\pi$ bonds that might complicate the analysis. A larger, and more crowded $\mathrm{NMe}_{3}$ base was considered as well, as were the highly nucleophilic $\mathrm{F}^{-}$and $\mathrm{Br}^{-}$anions. In each case, the base was initially positioned directly opposite the F atom of FTR 3 and the entire geometry of the complex fully optimized.

Quantum calculations were carried out via the Gaussian-09 ${ }^{76}$ program. MP2 was used in order to account for electron correlation. The aug-cc-pVDZ basis set was applied to all atoms with the exception of $\mathrm{Sn}$ and $\mathrm{Pb}$ which were represented by the aug-cc-pVDZ-PP pseudopotential from the EMSL library ${ }^{77-78}$ which accounts for relativistic effects. This level of theory has demonstrated its accuracy and effectiveness in numerous previous studies ${ }^{79-87}$ of related systems.

All geometries were fully optimized, and checked to ensure they were true minima by frequency calculations. The binding energy, $\Delta \mathrm{E}$, was defined as the difference between the energy of the complex and the sum of the energies of the optimized monomers. This quantity was corrected by the counterpoise procedure to remove basis set superposition error ${ }^{88}$. The interaction energy of each dimer differs in that it involves the energies of the monomers within the context of their geometry within the dimer. As such, this quantity represents the interaction between two monomers that have already been deformed into the structures they will ultimately adopt within the dimer. Thus, the binding and interaction energies differ by the strain or deformation energy of each monomer that takes it from its optimized structure to that within the dimer.

Molecular electrostatic potentials surrounding each molecule were visualized via the Chemcraft program ${ }^{89}$ and quantified by the Multiwfn program ${ }^{90}$ to locate its maxima and minima on the isodensity surface corresponding to $\rho=0.001$ au. Charge transfer was evaluated by the Natural Bond Orbital (NBO) technique ${ }^{91}$. The AIM formalism elucidated bond paths through analysis of the topology of the electron density ${ }^{92-93}$, making use of the AIMALL program ${ }^{94}$.

\section{RESULTS}

\section{$\underline{3.1 \mathrm{~T}=\mathrm{Si}}$}

As the smallest of the four tetrel atoms considered here, one might expect Si to suffer from the largest degree of steric crowding. The geometries of various $\mathrm{FSiR}_{3} \cdots \mathrm{NH}_{3}$ equilibrium structures are pictured in Fig 1, 
and their salient characteristics summarized in Table 1. There is little evidence of substantial steric repulsion in the $\mathrm{FSiH}_{3} \cdots \mathrm{NH}_{3}$ complexes where the $\mathrm{N}$ is able to approach within $2.56 \AA$ of the $\mathrm{Si}$ atom. The binding energy is $5.49 \mathrm{kcal} / \mathrm{mol}$, which is fairly large, comparable to that in the classically H-bonded water dimer. Despite the nearly unimpeded approach of the two molecules, the formation of this complex induces a certain amount of strain in the $\mathrm{FSiH}_{3}$ molecule, amounting to $1.93 \mathrm{kcal} / \mathrm{mol}$. Much of this deformation energy arises from the bending back of the $\mathrm{H}$ atoms away from the approaching nucleophile, with the $\theta(\mathrm{FHN})$ angle dropping by $5^{\circ}$ from $107.7^{\circ}$ in the monomer to $102.8^{\circ}$ within the complex.

When the $3 \mathrm{H}$ atoms are enlarged to methyl groups, a new dynamic emerges. The larger $\mathrm{CH}_{3}$ is associated with a certain degree of steric repulsion with the $\mathrm{NH}_{3}$. But there is also the possibility that $\mathrm{H}$-bonds can be formed from an $\mathrm{H}$ atom of each methyl group to the $\mathrm{N}$. And these $\mathrm{H}$-bonds are favored by a laonger intermolecular separation which permits them to be less distorted from linearity. Another factor in this change is the electron-releasing property of the methyl groups. As may be seen in the first two rows of Table 2, the substitution of the three $\mathrm{H}$ atoms of $\mathrm{FSiH}_{3}$ by methyls reduces the maximum in the electrostatic potential at the $\sigma$-hole from 41 to $27 \mathrm{kcal} / \mathrm{mol}$. This decrease reduces the force pulling the $\mathrm{N}$ atom in toward the Si, permitting the $\mathrm{CH} \cdot \cdot \mathrm{N}$ H-bonds to better take hold. Consequently the $\mathrm{R}(\mathrm{Si} \cdot \cdot \mathrm{N})$ distance is much longer at $3.75 \AA$. The binding energy of $2.24 \mathrm{kcal} / \mathrm{mol}$ can be attributed more to the three $\mathrm{CH} \cdot \mathrm{N}$ H-bonds and less to a tetrel bond (see below).

One can counter the electron-releasing ability of the three methyl groups by replacing one or more of them with $\mathrm{CF}_{3}$ which ought to have an opposite effect. And indeed, Table 2 shows that each such substitution enhances the $\sigma$-hole magnitude by $3-7 \mathrm{kcal} / \mathrm{mol}$. It is thus no surprise to see that the tetrel bond is now able to overcome the $\mathrm{CH}^{*} \cdot \mathrm{N}$ HBs, and bring the $\mathrm{N}$ atom progressively closer. $\mathrm{R}(\mathrm{Si} \cdot \cdot \mathrm{N})$ diminishes from $3.75 \AA$ for $\mathrm{FSiMe}_{3}$ down to $2.39,2.21$, and $2.12 \AA$ as each such substitution is put in place. With this contraction comes a growing binding energy, from $2.11 \mathrm{kcal} / \mathrm{mol}$ for a single $\mathrm{CF}_{3}$ group up to $18.2 \mathrm{kcal} / \mathrm{mol}$ when all three are exchanged. The strength of this bond is reflected also in the contracting intermolecular distance, a scant $2.12 \AA$ for the trisubstituted Lewis acid. Note that this closer proximity comes with a price in the form of growing distortion energy of the Lewis acid, rising all the way up to $17.3 \mathrm{kcal} / \mathrm{mol}$ for $\mathrm{FSi}\left(\mathrm{CF}_{3}\right)_{3}$. The binding energy of $18.2 \mathrm{kcal} / \mathrm{mol}$ thus comes at the expense of this large deformation energy, so must reflect quite a strong attractive force. Indeed, when the deformation energies are accounted for, the final column of Table 1 shows that the interaction energy in the $\mathrm{FSi}\left(\mathrm{CF}_{3}\right)_{3} \cdots \mathrm{NH}_{3}$ complex is more than $35 \mathrm{kcal} / \mathrm{mol}$, quite a strong interaction. This quantity is enlarged by some $10-11 \mathrm{kcal}$ for each $\mathrm{CH}_{3}$ to $\mathrm{CF}_{3}$ substitution, reflecting the sensitivity of the tetrel bond to the electron-withdrawing capacity of the latter group.

A further enlargement of the $\mathrm{R}$ groups to isopropyl (Iso) makes it more difficult for the $\mathrm{NH}_{3}$ base to approach the Si. There is a minimum that occurs for $\mathrm{R}=3.091 \AA$. Similar to the trimethyl case, the tetrel bond 
is reinforced by several $\mathrm{CH}^{*} \mathrm{~N}$ HBs. Because of the long intermolecular distance, the binding energy is rather small, and is in fact very slightly repulsive $(\Delta \mathrm{E}=+0.2 \mathrm{kcal} / \mathrm{mol})$ when counterpoise corrections are included. There is a small distortion energy which makes the interaction energy between the pre-deformed monomers attractive, by $2.3 \mathrm{kcal} / \mathrm{mol}$.

Interestingly, for the tri-isopropyl case, one sees a competition of sorts between two possibilities. If the isopropyl groups are rotated a bit, one can generate a second minimum, with a much closer approach of the $\mathrm{Si}$ and $\mathrm{N}$ atoms, $\mathrm{R}=2.50 \AA$. However, this second minimum is higher in energy than the first, by some $6 \mathrm{kcal} / \mathrm{mol}$. Due to the much closer proximity of the two molecules, there is a correspondingly higher distortion energy of $14.2 \mathrm{kcal} / \mathrm{mol}$. Thus the interaction energy in the last column of Table 1 shows a larger interaction energy for this contracted dimer, $7.4 \mathrm{vs} 2.3 \mathrm{kcal} / \mathrm{mol}$ for the more stable conformation. In other words, the steric repulsions present in certain tetrel bonding situations can lead in some cases to either i) a long and weak tetrel bond, perhaps reinforced by secondary HBs or ii) a short but stronger tetrel bond which must overcome strong internal deformations and may result in a positive overall value of $\Delta \mathrm{E}$.

As a final point, one can again strengthen the interaction by introduction of an electron-withdrawing $\mathrm{CF}_{3}$ group. As may be seen in Table 2, the inclusion of only a single such group ramps $\mathrm{V}_{\mathrm{s}, \max }$ up from 9.9 to 23.1 $\mathrm{kcal} / \mathrm{mol}$. This powerful $\sigma$-hole pulls the $\mathrm{NH}_{3}$ in toward the $\mathrm{Si}$ to a distance of only $2.38 \AA$, and eliminates any secondary minimum at a longer separation. The small binding energy of only $2.7 \mathrm{kcal} / \mathrm{mol}$ masks a large distortion energy of $10.3 \mathrm{kcal} / \mathrm{mol}$ which leads to an interaction energy of $13.0 \mathrm{kcal} / \mathrm{mol}$, quite similar to the case where a single Me group is replaced by $\mathrm{CF}_{3}$.

The replacement of each of the three isopropyl groups by the still larger tert-butyl (Tb) groups, can be anticipated to add a higher degree of steric hindrance. Nonetheless, the $\mathrm{N}$ atom can still approach within $2.52 \AA$ of the central $\mathrm{Si}$ atom. However, the repulsion is reflected in the positive $\Delta \mathrm{E},+10.8 \mathrm{kcal} / \mathrm{mol}$. As the two molecules pull one another together, the three t-butyl groups must move apart to make room for the approaching ligand. As may be seen in the next column of Table 1, the strain induced in the FSiTb 3 molecule amounts to $17.4 \mathrm{kcal} / \mathrm{mol}$. When this deformation energy is taken into account, the interaction energy between the two monomers in the complex, once they have appropriately distorted, is attractive and equal to $-6.6 \mathrm{kcal} / \mathrm{mol}$. Due to the positive value of $\Delta \mathrm{E}$, it was thought that perhaps there might be a second minimum with a longer intermolecular separation, as was observed for FSiIso3. However, no such minimum was found. It might be noted that the properties of $\mathrm{V}_{\mathrm{s}, \max }$ for $\mathrm{FSiTb}_{3}$ are unlike most of the Lewis acids in Table 2 (see below).

Rather than incorporation of alkyl groups of increasing size, another means of introducing steric repulsions into the Lewis acids is the replacement of the three $\mathrm{H}$ atoms of $\mathrm{FSiH}_{3}$ by halogen atoms of increasing size. Although such substitutions also introduce the possibility that $\mathrm{NH}^{\cdot} \cdot \mathrm{X}$ HBs can compete with the desired $\mathrm{FSi} \cdot \cdot \mathrm{N}$ tetrel bond, the equilibrium geometry of $\mathrm{FSiX}_{3}{ }^{\circ} \mathrm{NH}_{3}$ is characterized by a linear $\mathrm{FSi} \cdot{ }^{*} \mathrm{~N}$ tetrel bond for $\mathrm{X}=\mathrm{Cl}$, 
$\mathrm{Br}$, and I, as exhibited in Figs 2a, 2b, and 2c, respectively. The binding energies for these three trihalogenated Lewis acids diminish from 5.5 to $3.3 \mathrm{kcal} / \mathrm{mol}$ as the halogen is enlarged and gets progressively less electronwithdrawing, as may be seen in the last three rows of Table 1 . The $\mathrm{R}(\mathrm{Si} \cdot \cdot \mathrm{N})$ tetrel bond lengths are rather short, around $2.1 \AA$ for these three halogen substitutions, suggesting any detrimental effects from steric repulsions are overshadowed by the stronger tetrel bonds connected with the electron-withdrawing halogen substituents. The close approach of the two monomers does in fact lead to very substantial monomer deformation energies, between 15 and $20 \mathrm{kcal} / \mathrm{mol}$. When corrected by these distortions, the interaction energies are quite large, ranging between $18 \mathrm{kcal} / \mathrm{mol}$ for $\mathrm{FSiI}_{3}$ up to $25 \mathrm{kcal} / \mathrm{mol}$ for $\mathrm{FSiCl}_{3}$. So even though these halogenated Lewis acids incur quite large monomer deformations, their attraction toward the base outweighs this crowding effect. It might be added parenthetically, that the situation is quite different when $\mathrm{Si}$ is replaced by the smaller $\mathrm{C}$ atom. The weakness of any $\mathrm{C} \cdot \mathrm{N}$ tetrel bond is easily overwhelmed by the $\mathrm{NH} \cdot \cdot \mathrm{X}$ HBs, which are in fact observed in the equilibrium geometries for $\mathrm{X}=\mathrm{Cl}$ and $\mathrm{Br}$.

\subsubsection{Analysis of Wave Functions}

Some further insights into the nature of the binding within these complexes can be gleaned from Table 2. The first column displays the maximum in the molecular electrostatic potential (MEP) of each Lewis acid monomer, on the $\rho=0.001$ au isodensity surface, which corresponds to the $\sigma$-hole position, viz. directly opposite the $\mathrm{F}$ atom. This quantity is fairly large, $41.0 \mathrm{kcal} / \mathrm{mol}$ for the unsubstituted $\mathrm{SiH}_{3}$. As noted in the second column of Table 2, this point lies $1.940 \AA$ away from the Si atom. The replacement of the three $\mathrm{H}$ atoms by electron-releasing methyl groups lowers $\mathrm{V}_{\mathrm{s}, \max }$ by $34 \%$, down to $26.9 \mathrm{kcal} / \mathrm{mol}$, while also displacing it $0.2 \AA$ further away from the central $\mathrm{Si}$ atom. This drop in $\mathrm{V}_{\mathrm{s}, \max }$ can be recovered by replacing each methyl group by the electron-withdrawing $\mathrm{CF}_{3}$, with each such substitution providing a boost of roughly $5 \mathrm{kcal} / \mathrm{mol}$, as indicated earlier.

The addition of larger isopropyl (Iso) groups adds an interesting wrinkle. It was noted in Table 1 that there are two minima for the $\mathrm{FSiIsO}_{3} \cdots \mathrm{NH}_{3}$ complex, with $\mathrm{R}$ differing by $0.5 \AA$. The two structures differ in the orientations of the isopropyl groups. If these groups are situated as they are in the slightly more stable structure a, with the longer R, the maximum in the MEP is $22.0 \mathrm{kcal} / \mathrm{mol}$, and lies $2.24 \AA$ from $\mathrm{Si}$. But the reorientation of the isopropyl groups which permits the closer approach of the $\mathrm{NH}_{3}$ pulls this point $0.8 \AA$ further away from $\mathrm{Si}$, and drops its value to less than half, at $9.9 \mathrm{kcal} / \mathrm{mol}$. The replacement of one of these Iso groups by $\mathrm{CF}_{3}$ eliminates the second, and more distant, maximum in the MEP, and raises the value of $\mathrm{V}_{\mathrm{s}, \max }$ back up over 20 $\mathrm{kcal} / \mathrm{mol}$. The value of this maximum for $\mathrm{FSiTb}_{3}$ is similar to structure a for $\mathrm{FSiIsO}_{3}$, while lying further away from $\mathrm{Si}$.

The values of $\mathrm{V}_{\mathrm{s} \text {,max }}$ for the three $\mathrm{FSiX}_{3}$ monomers in the last three rows of Table 2 are quite sensitive to the nature of the halogen. The most electron-withdrawing $\mathrm{Cl}$ substituents yield a value of $27.0 \mathrm{kcal} / \mathrm{mol}$, which is 
reduced to half that amount for $\mathrm{FSiI}_{3}$. This point moves progressively further from the central $\mathrm{Si}$ atom as the $\mathrm{X}$ atom becomes larger, out to $2.41 \AA$ for $\mathrm{FSiI}_{3}$. It might be interesting to note that even with these three electronwithdrawing substituents, $\mathrm{V}_{\mathrm{s} \text {, max }}$ remains lower than for the unsubstituted $\mathrm{FSiH}_{3}$, and generally lower than $\mathrm{FSiMe}_{3}$, despite the weakness of the tetrel bonds involving the latter two monomers. Indeed, $\mathrm{FSiI}_{3}$ has a $\mathrm{V}_{\mathrm{s}, \mathrm{max}}$ that is as low as any of the other acids considered here. This observation contrasts with the rather high interaction energies of the $\mathrm{FSiX}_{3}$ acids.

One can obtain an alternate view of the strength of the intermolecular interaction via AIM analysis of the topography of the electron density of each complex. In particular, the density at the bond critical point connecting a pair of atoms is thought to be directly related to the strength of the noncovalent bond ${ }^{25,95-105}$. This quantity is reported as $\rho_{\mathrm{BCP}}$ in Table 2 . So for example, the density at this point is equal to 0.0233 au in the bond connecting $\mathrm{Si}$ with $\mathrm{N}$ in the $\mathrm{FSiH}_{3} \cdot \mathrm{NH}_{3}$ heterodimer, as displayed in the first row. When the three $\mathrm{H}$ atoms of $\mathrm{FSiH}_{3}$ are replaced by methyl groups, the bond path between $\mathrm{Si}$ and $\mathrm{N}$ disappears, and is replaced by three such paths, each connecting $\mathrm{N}$ with one $\mathrm{H}$ atom of each methyl group. It is for this reason that the $\mathrm{R}(\mathrm{Si} \cdot \cdot \mathrm{N})$ distance is so long in this complex, as noted in Table 1 . The $\mathrm{Si} \cdot \cdot \mathrm{N}$ bond path reappears when one of the methyl groups is replaced by $\mathrm{CF}_{3}$, with $\rho=0.0325 \mathrm{au}$. This bond is augmented by a weaker bond between $\mathrm{N}$ and one of the $\mathrm{F}$ atoms of the $\mathrm{CF}_{3}$ group. The latter bond is not present in the dimers containing two and three $\mathrm{CF}_{3}$ groups, and $\rho_{\mathrm{BCP}}$ grows continuously with each such replacement, up to 0.055 au for the trisubstituted species. This increase in the AIM quantity is mirrored in the binding energy $\Delta \mathrm{E}$, and even more so in the interaction energy.

There are two minima for the FSiIso 3 complex. The AIM data for the more stable of the two, structure a, reflects the long $\mathrm{R}\left(\mathrm{Si}^{\cdot} \mathrm{N}\right)$ distance in that there is no bond path between these two atoms. Instead, the complex is held together by three $\mathrm{N} \cdot \mathrm{H}$ H-bonds, one to each isopropyl group, and a $\mathrm{C} \cdot \mathrm{N}$ bond which might be characterized as a tetrel bond to one $\mathrm{C}$ of an isopropyl group. It is thus not surprising that this complex is only weakly bound. The electron-withdrawing capacity of a $\mathrm{CF}_{3}$ group, when substituted for one isopropyl reestablishes the $\mathrm{Si}^{*} \mathrm{~N}$ tetrel bond, in addition to providing a negative value of $\Delta \mathrm{E}$. This bond is elongated and weakened, for the tri-t-butyl derivative, and $\Delta \mathrm{E}$ becomes positive once again, with $\rho_{\mathrm{BCP}}$ dipping to $0.0264 \mathrm{au}$. The largest of all the values of $\rho_{\mathrm{BCP}}$ are associated with the halogenated $\mathrm{FSiX}_{3}$ acids in the last three rows of Table 2 .

NBO offers a means of examining charge transfers, in particular those between individual orbitals, as an alternate window into the nature of intermolecular interactions. In most cases of bonds of the tetrel type examined here, the chief intermolecular transfer takes charge from the $\mathrm{N}$ lone pair into the $\sigma^{*}(\mathrm{Si}-\mathrm{F})$ antibonding orbital. These quantities are reported in the penultimate column of Table 2 and show that there are other interorbital transfers that contribute to the interaction. In the $\mathrm{FSiH}_{3} \cdots \mathrm{NH}_{3}$ complex for example, the Si-F 
transfer perturbation energy E(2) of $17.97 \mathrm{kcal} / \mathrm{mol}$ is supplemented by transfers of $3.90 \mathrm{kcal} / \mathrm{mol}$ into each of the three Si-H antibonding orbitals. Hence while AIM would attribute the binding here to be solely due to the $\mathrm{Si} \cdot{ }^{\circ} \mathrm{N}$ tetrel bond, NBO would assign a substantial contribution from three $\mathrm{SiH}^{*} \cdot \mathrm{N}$ H-bonds. The situation changes for $\mathrm{FSiMe}_{3}{ }^{\cdots} \mathrm{NH}_{3}$ where AIM finds no evidence of a tetrel bond, whereas $\mathrm{NBO}$ again identifies not only the three $\mathrm{CH}^{*} \cdot \mathrm{N}$ H-bonds characterized by AIM, but also a weak tetrel bond. Indeed, NBO finds there is a tetrel bond in all cases, even in the long $\mathrm{Si}^{\cdot} \mathrm{N}$ bond in $\mathrm{FSiIso}{ }_{3} \cdots \mathrm{NH}_{3}$, where again AIM fails to locate a tetrel bond. It is characteristic of the NBO interpretation to find multiple sources of bonding. For example, the tetrel bond in $\mathrm{FSiMe}\left(\mathrm{CF}_{3}\right)_{2} \cdot \mathrm{NH}_{3}$ is augmented by transfer of charge from the $\mathrm{N}$ lone pair to all three of the $\sigma^{*}(\mathrm{Si}-\mathrm{C})$ antibonds even though these orbitals do not point directly to the $\mathrm{N}$, but which add nonetheless to the $\mathrm{Si} \cdot{ }^{*} \mathrm{~N}$ tetrel bond strength. These same subsidiary transfers to antibonds not directly opposite the $\mathrm{N}$ atom are in fact contributing factors to the tetrel bonds of all Lewis acids. The transfer into the $\sigma^{*}(\mathrm{SiF})$ antibonding orbital is rather large, $\sim 20 \mathrm{kcal} / \mathrm{mol}$, for the halogenated $\mathrm{FSiX}_{3}$ complexes. These contributions are supplemented by three secondary transfers, into each of the SiX antibonds, of nearly equal magnitude.

As there is a significant amount of charge that is being placed into the antibonding SiF orbital, one would expect to see a weakening and consequent lengthening of this bond. Such a stretch is indeed observed, as displayed in the last column of Table 2. The amount of this elongation varies from $0.005 \AA$ for the weak tetrel bond involving $\mathrm{FSiMe}_{3}$ to a maximum of $0.042 \AA$ for $\mathrm{FSi}\left(\mathrm{CF}_{3}\right)_{3}$ which is associated with the strongest $\mathrm{Si}$ tetrel bond of all those considered.

Summarizing the competition between attractive tetrel bonding and steric repulsions as substituents are placed on the $\mathrm{Si}, \mathrm{FSiH}_{3}$ is unimpeded so can form a fairly strong tetrel bond with $\mathrm{NH}_{3}$. The replacement of $\mathrm{H}$ by methyl groups induces a certain amount of steric hindrance, which is compensated to some degree by the formation of three $\mathrm{CH}^{*} \mathrm{~N}$ HBs, although they cannot fully make up for the loss of the tetrel bond. The $\mathrm{NH}_{3}$ is drawn in despite any steric repulsions as one or more methyl groups are replaced by the much more electronwithdrawing $\mathrm{CF}_{3}$, which amplifies the $\mathrm{Si} \sigma$-hole. The interaction is exothermic, even though formation of the complex must overcome monomer deformation energies between 11 and $17 \mathrm{kcal} / \mathrm{mol}$. In contrast, when the methyls are replaced by the larger isopropyl groups, the ensuing steric repulsions lead to an endothermic complexation. There is a fine balance observed between an attractive tetrel bond and steric repulsion, which leads to the presence of more than one minimum. One structure keeps the Si and N atoms $3.09 \AA$ apart, and another permits a closer association of $2.50 \AA$ but at the expense of a high monomer deformation energy. The same steric problems lead to an endothermic complexation, despite an attractive tetrel bond and a negative interaction energy, when the isopropyl groups are replaced by the even bulkier t-butyl. Although the $\mathrm{FSiX}_{3}$ Lewis acids suffer from substantial monomer deformation, the attraction is strong enough to pull the base in to short intermolecular contact distance, and an exothermic $\Delta \mathrm{E}$. 


\section{$\underline{3.2 \text { Heavier Tetrel Atoms }}$}

Given the observation that the Si atom has difficulty in accommodating a tetrel bond while covalently attached to certain bulky groups, it would be interesting to see how some of the heavier tetrel atoms might fare in this regard. One might expect that their larger size might expand the space around them, pushing the bulky groups further away, and perhaps better make room for an incoming Lewis base. There should also be a greater attractive force, based on the idea that along with larger atomic size will come lesser electronegativity and higher polarizability, both factors that should enhance the intensity of a $\sigma$-hole.

The ability of the heavier tetrel atoms to enable noncovalent bonding to a $\mathrm{NH}_{3}$ molecule is summarized in Table 3, and their full geometries illustrated in Fig 3. $\mathrm{FGeH}_{3}$ is nearly unimpeded, allowing the $\mathrm{N}$ to approach within $2.63 \AA$, only $0.07 \AA$ longer than in the case of the Si analogue, as evident in Fig 3 a. The binding energy of $-5.8 \mathrm{kcal} / \mathrm{mol}$ is slightly stronger than for the lighter Si analogue. And the heavier molecule suffers a 0.5 $\mathrm{kcal} / \mathrm{mol}$ lesser distortion energy. As in the Si case, the replacement of $\mathrm{H}$ atoms by methyl groups in Fig $3 \mathrm{~b}$ again reduces the binding energy, but with the difference that the $\mathrm{N}$ atom is not pushed as far from Ge as it is from $\mathrm{Si}$, approaching to within $2.78 \AA$. Enlargement of the substituents to isopropyl groups in Fig $3 \mathrm{c}$ does not lead to the same steric problems for the larger Ge: The $\mathrm{NH}_{3}$ approaches to within $2.82 \AA$, without a second, more distant, minimum, and the binding energy is clearly exothermic. Note also that the deformation energy of $\mathrm{FGeIsO}_{3}$ is only $2.4 \mathrm{kcal} / \mathrm{mol}$ in this complex, as compared to more than $14 \mathrm{kcal} / \mathrm{mol}$ for the $\mathrm{Si}$-analogue.

The steric hindrance does become a problem, though, when t-butyl groups are placed on the Ge. Although the $\mathrm{N}$ can approach to within $2.67 \AA$ in Fig $3 \mathrm{~d}$, the large deformation energy of $12.7 \mathrm{kcal} / \mathrm{mol}$ leads to an endothermic binding energy of $+6.6 \mathrm{kcal} / \mathrm{mol}$, a situation similar to that of its smaller $\mathrm{FSiTb}_{3}$ cousin. The possibility of a second minimum, with longer $\mathrm{R}$, was hence considered by a second optimization that began with $\mathrm{R}=3.0 \AA$, but this did not lead to a separate minimum.

The situation changes for the larger tetrel atoms $\mathrm{Sn}$ and $\mathrm{Pb}$. Even when encumbered by three t-butyl substituents, there is still ample room for the approach of the base, leading to negative values of $\Delta \mathrm{E}$. $\mathrm{NH}_{3}$ approaches to within 2.65 and $2.85 \AA$, respectively, for $\mathrm{FSnTb}_{3}$ and $\mathrm{FPbTb}_{3}$, as indicated in Figs $3 \mathrm{e}$ and $3 \mathrm{f}$. Moreover, the deformation energies become progressively smaller, lowering from $12.7 \mathrm{kcal} / \mathrm{mol}$ for $\mathrm{FGeTb}_{3}$, down to 6.4 for $\mathrm{FSnTb}_{3}$, and as little as $2.9 \mathrm{kcal}$ for the larger $\mathrm{FPbTb}_{3}$. This reduction in the steric repulsion also enables the binding energy to become progressively more exothermic, -3.4 and $-4.8 \mathrm{kcal} / \mathrm{mol}$ for these two complexes, respectively. In terms of the interaction energy between pre-distorted monomers in the last column of Table 3, it is the intermediate $\mathrm{FSnTb}_{3}$ which forms the strongest native bond of $-9.8 \mathrm{kcal} / \mathrm{mol}$, although Ge and $\mathrm{Pb}$ are not far behind. It is noted finally that perusal of the data in the penultimate columns of Tables 1 and 3 demonstrates that the $\mathrm{NH}_{3}$ base undergoes very little distortion as it approaches any of the Lewis acids, as it is 
the latter that must distort to accommodate the base. The possibility of a second minimum with a longer value of R was considered in both cases, with none found.

\subsubsection{Analysis of Wave Functions}

The intensity and locations of the sigma holes in these heavier tetrel Lewis acids reflect some of the trends witnessed in the energetics. As the three $\mathrm{H}$ atoms of $\mathrm{FGeH}_{3}$ are replaced by methyl, isopropyl, and then t-butyl groups, there is a steady erosion of the magnitude of $\mathrm{V}_{\mathrm{s}, \max }$, as may be seen in Table 4. As occurred in the triisopropyl $\mathrm{Si}$ monomer, the maximum in the MEP moves some distance away from the tetrel atom in $\mathrm{FGeTb}_{3}$, longer than $3 \AA$, which is in part responsible for its particularly small magnitude of only $13.9 \mathrm{kcal} / \mathrm{mol}$. The dropping value of $\mathrm{V}_{\mathrm{s}, \max }$ as the substituent is enlarged is associated with the generally diminishing binding and interaction energies although the latter energetic patterns are disrupted for the trimethyl derivative. The enlargement of the tetrel atom from $\mathrm{Ge}$ to $\mathrm{Sn}$ to $\mathrm{Pb}$ intensifies the $\sigma$-hole without pulling it any further away from the tetrel atom. This trend conforms to $\Delta \mathrm{E}$ but not to $\mathrm{E}_{\text {int. }}$

AIM and NBO analyses can again offer insights into the sources of bonding in these complexes. The electron density at the $\mathrm{Ge} \cdot{ }^{*} \mathrm{~N}$ bond critical point is lowest for the methyl and isopropyl derivatives. This trend is consistent with $\mathrm{E}_{\text {int, }}$ although not with $\Delta \mathrm{E}$ which must contend with monomer deformation energies. This same quantity is unaffected by the transition from $\mathrm{Ge}$ to $\mathrm{Sn}$ but is diminished for $\mathrm{Pb}$, a trend which does not mirror either of the energetic parameters. Note that as in the Si cases in Table 2, there are several subsidiary bond paths involving the $\mathrm{N}$ atom which augment $\mathrm{T} \cdot \mathrm{N}$ to some degree. For example, all of the complexes involving $\mathrm{Tb}_{3}$ species show evidence of one or more $\mathrm{CH} \cdot \mathrm{N} \mathrm{HBs}$.

Like the AIM values of $\rho_{\mathrm{BCP}}$, the Ge-F values of $\mathrm{E}(2)$ are smallest for $\mathrm{FGeMe}_{3}$ and $\mathrm{FGeIsO}$. $\mathrm{NBO}$ suggests a number of other interactions as well. Most surprising of these is the set of three $\mathrm{GeH} \cdot \cdot \mathrm{N}$ HBs in the $\mathrm{FGeH}_{3}$ case, which are not verified by AIM. For the larger substituents, one sees charge transfer into all three $\sigma^{*}(\mathrm{Ge}-$ C) antibonding orbitals, an interaction which differs from the simpler $\mathrm{CH} \cdot{ }^{*} \mathrm{~N}$ HBs indicated by AIM. Enlargement of the tetrel atom induces a small but steady drop in the $\mathrm{N}_{\mathrm{lp}} \rightarrow \sigma^{*}(\mathrm{~T}-\mathrm{F}) \mathrm{E}(2)$, which is not mirrored by the energetics. As in the Ge analogue, the $\mathrm{Tb}_{3}$ derivatives of $\mathrm{Sn}$ and $\mathrm{Pb}$ show substantial charge transfer into the $\sigma^{*}(\mathrm{~T}-\mathrm{C})$ orbitals which are not well aligned for such a transfer. Nonetheless, the particularly large such transfers for $\mathrm{FSnTb}_{3}$ may be responsible for the large magnitude of $\mathrm{E}_{\text {int }}$ for its complex with $\mathrm{NH}_{3}$.

As in the case with the Si-containing systems, there is again a stretch in the T-F bond caused by charge transfer into its antibonding orbital. As may be seen in the last column of Table 4, these stretches vary between $0.022 \AA$ for $\mathrm{FGeIso}_{3}$ up to a maximum of $0.049 \AA$ for $\mathrm{FPbTb}_{3}$. Comparison with the stretches for the Si systems in Table 2 suggests that these elongations are larger for the heavier tetrel atoms, when compared to the actual energetics. 


\section{$\underline{3.3 \text { Correlations between Properties }}$}

One might anticipate there to be some connection between the various metrics that arise from analysis of the wave functions and the geometries and energetics of these complexes. For example, the stretching of the T-F bond ought to increase as more charge is transferred into the $\sigma^{*}(\mathrm{~T}-\mathrm{F})$ antibonding orbital. The correlation between these two quantities is modest, with a correlation coefficient of 0.88 , as indicated in the first row of Table 5. The same charge transfer should have a direct influence upon the interaction energy, but their correlation coefficient is only a poor 0.56 . On the other hand, it was shown above that there is a good deal of charge that is transferred into other antibonding orbitals of the Lewis acid. When all of these contributions in Tables 2 and 4 are summed, this total $\mathrm{E}(2)$ correlates much better with the interaction energy, with $\mathrm{R}^{2}=0.89$. Excellent prediction of the interaction energy is also achieved when considering the density at the $\mathrm{T} \cdot \mathrm{N}$ bond critical point, with a correlation coefficient of 0.88 . Due to the differing sizes of the four T atoms, one would expect only a rough correlation between the interaction energy and $\mathrm{R}(\mathrm{T} \cdot \mathrm{N})$. And indeed, the correlation coefficient for this pair of parameters is only 0.75 . The importance of due consideration of steric crowding is evident in the last two rows of Table 5. When the binding energy $\Delta \mathrm{E}$, prior to corrections for monomer deformation, is used in place of the interaction energy, these correlations deteriorate. For example, the correlation coefficient involving $\rho_{\mathrm{BCP}}$ drops from 0.88 to 0.47 . Likewise for the total NBO term, which sees a deterioration from 0.89 to 0.49 .

\section{$\underline{3.4 \text { Bulkier Lewis Base }}$}

As it is clear that a small base like $\mathrm{NH}_{3}$ changes its geometry very little as it approaches even the bulkiest of the Lewis acids, it is natural to wonder how enlarging the base might affect its ability to engage in tetrel bonding. The three $\mathrm{H}$ atoms of $\mathrm{NH}_{3}$ were thus enlarged to methyl groups and allowed to interact with three of the more crowded Lewis acids. FGeIso 3 was the largest Ge-acid for which $\Delta \mathrm{E}$ was negative (see Table 3 ) when interacting with $\mathrm{NH}_{3}$. The enlargement of the base elongated the equilibrium $\mathrm{R}(\mathrm{Ge} \cdot \mathrm{N})$ distance by $0.2 \AA$ from 2.823 to $3.027 \AA$. On the other hand, the more basic character of $\mathrm{NMe}_{3}$ also raised the binding energy a bit, from -3.64 to $-6.22 \mathrm{kcal} / \mathrm{mol}$. The longer intermolecular separation reduces the deformation energy slightly, to $1.74 \mathrm{kcal} / \mathrm{mol}$. The interaction energy within the complex then is equal to $-7.96 \mathrm{kcal} / \mathrm{mol}$ for $\mathrm{NMe}_{3}$, slightly greater than the $-6.02 \mathrm{kcal} / \mathrm{mol}$ for the smaller $\mathrm{NH}_{3}$. The stronger interaction with the larger base occurs despite a less negative $\mathrm{V}_{\mathrm{s}, \min }$ in the $\mathrm{N}$ lone pair area: $-34.46 \mathrm{kcal} / \mathrm{mol}$ for $\mathrm{NMe}_{3}$, vs $-40.16 \mathrm{kcal} / \mathrm{mol}$ for $\mathrm{NH}_{3}$. Also $\mathrm{NMe}_{3}$ has a dipole moment only half that of $\mathrm{NH}_{3}$, which ought to reduce the electrostatic attraction in the complex involving the larger base. So although stretching the $\mathrm{R}(\mathrm{Ge} \cdot \mathrm{N})$ separation, the enlarged base is still able to engage in a thermodynamically viable tetrel bond, slightly stronger, even if longer, than that noted for $\mathrm{NH}_{3}$.

The combination of t-butyl groups with the methyl groups on the base leads to complications in identifying truly tetrel-bonded complexes. The results of geometry optimization become highly dependent upon the 
structures chosen for the individual monomers. Some optimizations led to minima on the surface, but these were quite shallow, and not necessarily of low energy. In the case of $\mathrm{FPbTb}_{3}$, for example, two minima were located, one with $\mathrm{R}(\mathrm{Pb} \cdot \mathrm{N})=2.80 \AA$, and another longer distance of $3.380 \AA$. However, both of these minima were higher in energy than the sum of isolated monomers, with positive $\Delta \mathrm{E}$. Even after correction of $\Delta \mathrm{E}$ by the monomer deformation energies, the resulting interaction energies remained positive. In these cases, then, one may infer that while the formation of tetrel bonds between these highly sterically hindered monomers may be possible in principle, each monomer must be able to rearrange from their optimal geometry before such an association can occur.

\section{$\underline{3.5}$ Anionic Bases}

One would expect that placing a negative charge on the Lewis base would amplify the attractive force, and so might better compete against any steric repulsive forces. The fluoride ion is also small enough that steric repulsions should be minimized. And indeed, when $\mathrm{F}^{-}$was permitted to interact with $\mathrm{FSiMe}_{3}$, it approached the

$\mathrm{Si}$ atom to within $1.828 \AA$, almost as short as the $\mathrm{Si}-\mathrm{F}$ bond within the monomer. The formation of this trigonal bipyramid structure is exothermic by $40.57 \mathrm{kcal} / \mathrm{mol}$. This situation is clearly quite distinct from the complex of this same Lewis acid with the neutral $\mathrm{NH}_{3}$, where the $\mathrm{R}(\mathrm{Si} \cdot \cdot \mathrm{N})$ distance is $3.753 \AA$, and the binding energy is only $2.2 \mathrm{kcal} / \mathrm{mol}$. The situation is much the same for the bulkier FSiIso 3 , which also forms a trigonal bipyramid complex with $\mathrm{F}^{-}$, with $\mathrm{R}\left(\mathrm{Si}^{*} \cdot \mathrm{F}\right)=1.830 \AA$, and $\Delta \mathrm{E}=-44.76 \mathrm{kcal} / \mathrm{mol}$. Again, the small fluoride is able to evade the steric repulsions which had plagued the complex with the neutral base, leading the latter to positive values of $\Delta \mathrm{E}$. The $\mathrm{FGeTb}_{3}$ acid had also suffered from steric constraints when combined with $\mathrm{NH}_{3}$, resulting in a positive $\Delta \mathrm{E}$. Replacement of the neutral base by $\mathrm{F}^{-}$fully relieves these issues, leading to a trigonal bipyramid structure, and with $\Delta \mathrm{E}=-54.16 \mathrm{kcal} / \mathrm{mol}$.

Enlargement of the anion to $\mathrm{Br}^{-}$reduces the binding energy relative to $\mathrm{F}^{-}$, but still avoids steric restrictions, and permits formation of a tetrel-bonded complex. When combined with FSiIso3, the bromide approaches to within $3.143 \AA$ of $\mathrm{Si}$, and $\Delta \mathrm{E}=-13.88 \mathrm{kcal} / \mathrm{mol}$. The $\mathrm{FGeTb}_{3}$ acid had its steric constraints relieved by $\mathrm{F}^{-}$. Replacement of $\mathrm{NH}_{3}$ by the larger $\mathrm{Br}^{-}$anion again relieves the repulsive forces, allowing this anion to approach the Ge atom to within $3.015 \AA$, and yielding a healthy $-9.58 \mathrm{kcal} / \mathrm{mol}$ for $\Delta \mathrm{E}$. In summary, then, the enhanced attractive force engendered by anions is sufficient to overcome steric issues which limit the tetrel bonding of neutral bases.

\section{SUMMARY AND DISCUSSION}

In summary, $\mathrm{FSiR}_{3}$ displays some evidence of steric hindrance to the formation of a tetrel bond with $\mathrm{NH}_{3}$ when the $\mathrm{R}$ is either isopropyl or t-butyl. While the $\mathrm{N}$ can approach to within about $2.5 \AA$ of the $\mathrm{Si}$ atom, the binding energy is positive, due to deformations that occur within the Lewis acid to accommodate the incoming base. Even with smaller R=Me groups, steric forces are present that push the base out to a longer distance. The 
incorporation of electron-withdrawing halogen atoms as substituents on $\mathrm{Si}$ act to pull the $\mathrm{NH}_{3}$ in rather close, and thereby engender a good deal of monomer geometry deformation. But even so, the binding energy is negative. Larger tetrel atoms are less electronegative and more polarizable, so exert a stronger pull on the base. These $\mathrm{FTR}_{3}$ molecules also appear more flexible, and better able to distort to allow the base to approach. The binding energy of $\mathrm{FGeR}_{3}$ is negative even for the isopropyl $\mathrm{R}$ but becomes positive for t-butyl. Both the $\mathrm{Sn}$ and $\mathrm{Pb}$ analogues can fully accommodate $\mathrm{NH}_{3}$ with a negative $\Delta \mathrm{E}$ and small $\mathrm{R}(\mathrm{T} \cdot \cdot \mathrm{N})$ even for the bulky t-butyl group. Further stress is placed on the tetrel bonds when the larger $\mathrm{NMe}_{3}$ base is considered.

In any set of quantum calculations, there is always some question as to the accuracy of the particular level of theory that has been chosen. For example, the next size larger basis set would be the triple-valence aug-ccpVTZ set (and corresponding aug-cc-pVTZ-PP for Sn and Pb). In past studies of similar sorts of noncovalent bonds, this expansion of basis set typically leads to a small increase in the interaction energy. As shown in Table 6 , these tetrel bonds are no exception. The rise in this quantity ranges from less than $1 \mathrm{kcal} / \mathrm{mol}$ to as much as $5 \mathrm{kcal} / \mathrm{mol}$ for the most strongly bound. On a percentage basis, this increase is more uniform, between 10 and 28\% Most importantly, the expansion of the basis set does not alter any of the trends encountered with aug-cc-pVDZ. Moreover, a good deal of past work has verified the strengthening of the interaction with the larger set, but more importantly, that the improvement of the correlation method from MP2 to CCSD(T), including extrapolation to a complete basis set, reverses this effect, leaving MP2/aug-cc-pVDZ data quite similar to the gold standard CCSD(T)/CBS values ${ }^{16,18,65,87,106-111}$.

A note of caution should be exercised in the search for minima in complexes such as these. In the case of the complexation of $\mathrm{NH}_{3}$ with $\mathrm{FSiIsO}_{3}$, for example, there are two separate minima. The more stable of the two occurs for an intermolecular separation of $3.1 \AA$, considerably longer than most tetrel bonds. If the two monomers are able to overcome an energy barrier as they continue to approach one another more closely, they reach a second minimum, with $\mathrm{R}=2.5 \AA$ and a legitimate tetrel bond. While this second minimum is less stable than the first by some $6.6 \mathrm{kcal} / \mathrm{mol}$, this energy rise, along with the energy barrier separating the two minima, is due largely to internal deformation energy within the monomers. Consequently, the interaction energy between the two monomers, in their pre-deformed geometries, is $-7.4 \mathrm{kcal} / \mathrm{mol}$ for the complex with the shorter intermolecular distance, as compared to only $-2.3 \mathrm{kcal} / \mathrm{mol}$ for the outer-sphere complex.

Possible manifestations of short and long-range minima can be quite varied, depending upon the nature of the tetrel atom. As indicated above, when three bulky isopropyl substituents are added to $\mathrm{Si}$, both of these minima occur, both with positive values of $\Delta \mathrm{E}$, and negative interaction energies. Replacement with the slightly bulkier tert-butyl groups removes the second, outer-sphere minimum. The sole remaining minimum has a very positive $\Delta \mathrm{E}$, but negative interaction energy between pre-distorted monomers. Enlargement of the tetrel atom to Ge eliminates the long-range minimum for both the isopropyl and t-butyl-substituted monomer. The 
tetrel-bonded structure for the former has a negative $\Delta \mathrm{E}$, but the enlarged monomer deformation energy leads to a positive $\Delta \mathrm{E}$ for the latter (with very similar interaction energies for the two).

There thus appears to be a clear and systematic trend that enlarging the tetrel atom reduces the consequences of steric crowding. Considering those Lewis acids with three t-butyl substituents, a tetrel bond can be formed for $\mathrm{Si}$, but with a very positive $\Delta \mathrm{E}$, which remains positive for $\mathrm{Ge}$. Both $\mathrm{Sn}$ and $\mathrm{Pb}$ allow negative binding energies to emerge. The progressive relaxation of steric repulsions is clear in the lowering distortion energies: 15.0, 12.7, 6.4, and $2.9 \mathrm{kcal} / \mathrm{mol}$ respectively for $\mathrm{Si}, \mathrm{Ge}, \mathrm{Sn}$, and $\mathrm{Pb}$. With these deformations accounted for, the remaining interaction energies within these same complexes are -4.9, -6.1, -9.8, and $-7.7 \mathrm{kcal} / \mathrm{mol}$. As indicated above, the addition of electron-releasing methyl substituents on the Lewis base adds to the binding energy of $\mathrm{FGeIso}_{3}$, as well as the interaction energy, even though the added steric repulsions of the new methyl groups stretch the tetrel bond by some $0.2 \AA$. The combination of this larger $\mathrm{NMe}_{3}$ base with t-butyl groups on the acid leads to real complications in bringing the two molecules together.

The situation can be further complicated by multiple minima for the monomers themselves. Again using the FSiIso3 system as an example, there are a number of orientations of the three isopropyl groups that can be envisioned. The particular arrangement that is most stable in the case of the monomer is not necessarily the same as the global minimum for the complex with $\mathrm{NH}_{3}$. In this particular case, the global minimum for the monomer lies some $1.5 \mathrm{kcal} / \mathrm{mol}$ lower than the geometry that corresponds to the most stable dimer. Failure of the isopropyl groups of the monomer to rearrange in preparation for complexation, which would need to overcome an energy barrier in addition to an overall less stable monomer, results in a complex that is 4.8 $\mathrm{kcal} / \mathrm{mol}$ less stable than the global minimum of the dimer.

The examination of the MEP of the Lewis acid monomer, and its sensitivity to its conformation, brings up another issue related to the steric crowding involved in tetrel bonds. As the base approaches, there is a substantial change in the acid's geometry. If instead of computing the MEP of the undistorted monomer, one instead considers the potential of the monomer within the context of the dimer, distorted to permit its complexation with $\mathrm{NH}_{3}$, the data can be quite different. Taking the $\mathrm{FSiIsO}_{3} \cdot \mathrm{NH}_{3}$ dimer as a prime example, in the case of the outer-sphere complex, with $\mathrm{R}(\mathrm{Si} \cdot \cdot \mathrm{N})=3.09 \AA, \mathrm{V}_{\mathrm{s}, \max }$ is located only $1.99 \AA$ from the Si atom, and is enlarged from 21.99 to $38.04 \mathrm{kcal} / \mathrm{mol}$. The distinction is even more dramatic for the tetrel-bonded structure b, with $\mathrm{R}=2.50 \AA$. Adjusting the $\mathrm{FSiIsO}_{3}$ monomer to its geometry within this complex brings the $\mathrm{V}_{\mathrm{s} \text {,max }}$ point in from 3.02 to $1.91 \AA$, and raises the density at this point by five-fold, to $49.28 \mathrm{kcal} / \mathrm{mol}$. This issue is not restricted to only $\mathrm{FSiIsO}_{3} \cdot \mathrm{NH}_{3}$ which is characterized by two separate minima. Even in the single minimum of $\mathrm{FSiTb}_{3} \cdot \mathrm{NH}$, the change of geometry of $\mathrm{FSiTb}_{3}$ from its optimized structure to that within the dimer raises $\mathrm{V}_{\mathrm{s} \text {,max }}$ from 11.14 to $49.89 \mathrm{kcal} / \mathrm{mol}$ and draws this point in from 3.22 to only $1.92 \AA$ from the Si nucleus. So while inspection of the MEP is of course a valuable tool in understanding the nature and strength of tetrel bonds, it is 
important to be wary of complications that arise in terms of which specific geometry is to be considered. This issue may not be restricted purely to tetrel bonds, as it has arisen previously ${ }^{112}$ in the context of certain pnicogen bonds.

There are a few prior results that offer points of comparison. An early spectral measurement ${ }^{32}$ of the tetrel bond length of $2.09 \AA$ in $\mathrm{FSiF}_{3} \cdots \mathrm{NH}_{3}$ is consistent with the distances of the related complexes in Table 1, and also confirms significant monomer geometric distortions. A study ${ }^{113}$ of the dimer of $\mathrm{Me}_{3} \mathrm{SnCN}$ at various levels of calculation found interaction energies for the $\mathrm{Sn} \cdot \mathrm{N}$ tetrel bond that are comparable to that computed here. The stronger tetrel bonds formed by $\mathrm{NMe}_{3} \mathrm{vs} \mathrm{NH}_{3}$ was verified ${ }^{35}$, as was the superiority of $\mathrm{Pb}$ and $\mathrm{Sn}$ over Ge and Si, and several studies ${ }^{36,43,52-53}$ confirm the enhanced strength when an anionic base is included. Grabowski ${ }^{114}$ had recently considered the tetrel bonding of $\mathrm{SnF}_{4}$ and $\mathrm{PbF}_{4}$ with $\mathrm{N}$ bases, and obtained data consistent with our own findings that significant deformation energies accompany the binding of these perhalogenated Lewis acids. The magnitudes of these distortion energies are smaller than those obtained here for $\mathrm{FSiX}_{3}$, consistent with the lesser distortions required to bind to the larger $\mathrm{Sn}$ and $\mathrm{Pb}$ atoms. This author ${ }^{114}$ also scanned available crystal structures and identified certain geometries with this tetrel-bonded Sn motif. A recent calculation of $\mathrm{FGeH}_{3} \cdots \mathrm{NH}_{3}{ }^{100}$ with a larger basis set yielded nearly identical binding and interaction energies as our own data in Table 3.

In a more general sense, the various forces involved in noncovalent, and indeed other bonds as well, derive from Coulombic forces involving nuclei and electrons, coupled with issues related to electron spin. Various components of the intermolecular forces, such as electrostatic, polarization, steric repulsions, and charge transfer all fall within this overall umbrella ${ }^{115-117}$. One can also argue that charge transfer is a form of polarization. Nonetheless, a separation into these various terms offers a solid and physically sound conceptual basis on which to better understand the nature of intermolecular forces, which have motivated countless analyses of this type ${ }^{118-124}$.

In conclusion, tetrel bonding can be quite strong, with interaction energies exceeding $35 \mathrm{kcal} / \mathrm{mol}$ for a pair of neutral molecules, and up to $54 \mathrm{kcal} / \mathrm{mol}$ for an anionic base. Even when all substituents are nonpolar alkyl groups, the interaction energy can reach $10 \mathrm{kcal} / \mathrm{mol}$. However, steric crowding is an issue that must be thoughtfully considered in the context of tetrel bonding. This issue becomes progressively more important as the substituents on the two molecules are enlarged. Its effects can be partially assuaged if the attractive force is particularly large, as for example for anionic bases, or for highly electron-withdrawing substituents on the Lewis acid. But even in such cases, there may be a high degree of monomer deformation which must be overcome in order for this bond to occur. 


\section{REFERENCES}

1. Gilli, G.; Gilli, P. The Nature of the Hydrogen Bond. Oxford University Press: Oxford, UK, 2009 ; p 313.

2. Desiraju, G. R.; Steiner, T. The Weak Hydrogen Bond in Structural Chemistry and Biology. Oxford: New York, 1999; p 507.

3. Scheiner, S. Hydrogen Bonding. A Theoretical Perspective. Oxford University Press: New York, 1997; p 375.

4. Legon, A. C. Tetrel, Pnictogen and Chalcogen Bonds Identified in the Gas Phase before They Had Names: A Systematic Look at Non-Covalent Interactions. Phys. Chem. Chem. Phys. 2017, 19, 1488414896.

5. Sánchez-Sanz, G.; Trujillo, C.; Alkorta, I.; Elguero, J. Enhancing Intramolecular Chalcogen Interactions in 1-Hydroxy-8-Yh-Naphthalene Derivatives. J. Phys. Chem. A 2017, 121, 8995-9003.

6. Grabowski, S. J. Hydrogen Bonds, and $\sigma$-Hole and $\pi$-Hole Bonds - Mechanisms Protecting Doublet and Octet Electron Structures. Phys. Chem. Chem. Phys. 2017, 19, 29742-29759.

7. Alkorta, I.; Elguero, J.; Del Bene, J. E. Azines as Electron-Pair Donors to $\mathrm{CO}_{2}$ for $\mathrm{N} \cdots \mathrm{C}$ Tetrel Bonds. $J$. Phys. Chem. A 2017, 121, 8017-8025.

8. Clark, T.; Hennemann, M.; Murray, J. S.; Politzer, P. Halogen Bonding: The $\sigma$-Hole. J. Mol. Model. 2007, 13, 291-296.

9. Murray, J. S.; Lane, P.; Politzer, P. A Predicted New Type of Directional Noncovalent Interaction. Int. J. Quantum Chem. 2007, 107, 2286-2292.

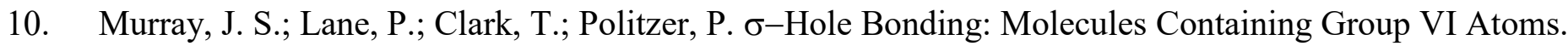
J. Mol. Model. 2007, 13, 1033-1038.

11. Alkorta, I.; Rozas, S.; Elguero, J. Charge-Transfer Complexes between Dihalogen Compounds and Electron Donors. J. Phys. Chem. A 1998, 102, 9278-9285.

12. Karpfen, A. Charge-Transfer Complexes between $\mathrm{NH}_{3}$ and the Halogens $\mathrm{F}_{2}, \mathrm{ClF}$, and $\mathrm{Cl}_{2}$,: An $\mathrm{Ab}$ Initio Study on the Intermolecular Interaction. J. Phys. Chem. A 2000, 104, 6871-6879.

13. Zierkiewicz, W.; Wieczorek, R.; Hobza, P.; Michalska, D. Halogen Bonded Complexes between Volatile Anaesthetics (Chloroform, Halothane, Enflurane, Isoflurane) and Formaldehyde: A Theoretical Study. Phys. Chem. Chem. Phys. 2011, 13, 5105-5113.

14. Riley, K. E.; Ford Jr, C. L.; Demouchet, K. Comparison of Hydrogen Bonds, Halogen Bonds, CH·П Interactions, and CX $\sqcap$ Interactions Using High-Level Ab Initio Methods. Chem. Phys. Lett. 2015, 621, 165-170.

15. Politzer, P.; Murray, J. S. A Unified View of Halogen Bonding, Hydrogen Bonding and Other $\sigma$-Hole Interactions. In Noncovalent Forces, Scheiner, S., Ed. Springer: Dordrecht, Netherlands, 2015; Vol. 19, pp 357-389.

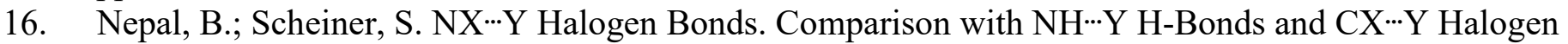
Bonds. Phys. Chem. Chem. Phys. 2016, 18, 18015-18023.

17. Iwaoka, M.; Komatsu, H.; Katsuda, T.; Tomoda, S. Quantitative Evaluation of Weak Nonbonded Se $\cdots$ F Interactions and Their Remarkable Nature as Orbital Interactions. J. Am. Chem. Soc. 2002, 124, 19021909.

18. Nziko, V. d. P. N.; Scheiner, S. S $\cdots \Pi$ Chalcogen Bonds between $\mathrm{SF}_{2}$ or $\mathrm{SF}_{4}$ and $\mathrm{C}-\mathrm{C}$ Multiple Bonds. $J$. Phys. Chem. A 2015, 119, 5889-5897.

19. Sanz, P.; Mó, O.; Yáñez, M. Characterization of Intramolecular Hydrogen Bonds and Competitive Chalcogen-Chalcogen Interactions on the Basis of the Topology of the Charge Density. Phys. Chem. Chem. Phys. 2003, 5, 2942-2947.

20. Azofra, L. M.; Alkorta, I.; Scheiner, S. Chalcogen Bonds in Complexes of SOXY (X, Y = F, Cl) with Nitrogen Bases. J. Phys. Chem. A 2015, 119, 535-541.

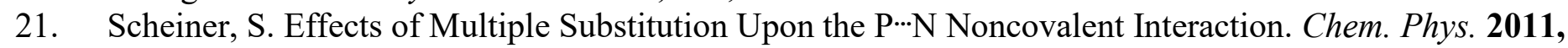
387, 79-84. 
22. Zierkiewicz, W.; Bieńko, D. C.; Michalska, D.; Zeegers-Huyskens, T. Theoretical Investigation of the Halogen Bonded Complexes between Carbonyl Bases and Molecular Chlorine. J. Comput. Chem. 2015, 36, 821-832.

23. Adhikari, U.; Scheiner, S. Effects of Charge and Substituent on the S $\cdots$ N Chalcogen Bond. J. Phys. Chem. A 2014, 118, 3183-3192.

24. Bauzá, A.; Mooibroek, T. J.; Frontera, A. $\Sigma$-Hole Opposite to a Lone Pair: Unconventional Pnicogen Bonding Interactions between $\mathrm{ZF}_{3}(\mathrm{Z}=\mathrm{N}, \mathrm{P}, \mathrm{As}$, and $\mathrm{Sb})$ Compounds and Several Donors. ChemPhysChem. 2016, 17, 1608-1614.

25. Del Bene, J. E.; Alkorta, I.; Elguero, J. The Pnicogen Bond in Review: Structures, Energies, Bonding Properties, and Spin-Spin Coupling Constants of Complexes Stabilized by Pnicogen Bonds. In Noncovalent Forces, Scheiner, S., Ed. Springer: Dordrecht, Netherlands, 2015; Vol. 19, pp 191-263.

26. Scheiner, S. Sensitivity of Noncovalent Bonds to Intermolecular Separation: Hydrogen, Halogen, Chalcogen, and Pnicogen Bonds. CrystEngComm 2013, 15, 3119-3124.

27. Sanchez-Sanz, G.; Trujillo, C.; Alkorta, I.; Elguero, J. Modulating Intramolecular P..N Pnictogen Interactions. Phys. Chem. Chem. Phys. 2016, 18, 9148-9160.

28. Scheiner, S.; Adhikari, U. Abilities of Different Electron Donors (D) to Engage in a P...D Noncovalent Interaction. J. Phys. Chem. A 2011, 115, 11101-11110.

29. Scheiner, S. Can Two Trivalent N Atoms Engage in a Direct N $\cdots$ N Noncovalent Interaction? Chem. Phys. Lett. 2011, 514, 32-35.

30. Bauzá, A.; Mooibroek, T. J.; Frontera, A. Tetrel-Bonding Interaction: Rediscovered Supramolecular Force? Angew. Chem. Int. Ed. 2013, 52, 12317-12321.

31. Rossi, A. R.; Jasinski, J. M. Theoretical Studies of Neutral Silane-Ammonia Adducts. Chem. Phys. Lett. 1990, 169, 399-404.

32. Ruoff, R. S.; Emilsson, T.; Jaman, A. I.; Germann, T. C.; Gutowsky, H. S. Rotational Spectra, Dipole Moment, and Structure of the $\mathrm{SiF}_{4}-\mathrm{NH}_{3}$ Dimer. J. Chem. Phys. 1992, 96, 3441-3446.

33. Urban, R. D.; Rouillé, G.; Takami, M. Free-Jet IR Spectroscopy of $\mathrm{SiF}_{4}-\mathrm{N}_{2}$ and $\mathrm{SiF}_{4}-\mathrm{CO}$ Complexes in the 10 Mm Region. J. Mol. Struct. 1997, 413-414, 511-519.

34. Levy, C. J.; Puddephatt, R. J. Rapid Reversible Oxidative Addition of Group 14-Halide Bonds to Platinum(II): Rates, Equilibria, and Bond Energies. J. Am. Chem. Soc. 1997, 119, 10127-10136.

35. Donald, K. J.; Tawfik, M. The Weak Helps the Strong: Sigma-Holes and the Stability of MF4·Base Complexes. J. Phys. Chem. A 2013, 117, 14176-14183.

36. Grabowski, S. J. Tetrel Bond- $\sigma$-Hole Bond as a Preliminary Stage of the $\mathrm{S}_{\mathrm{n}} 2$ Reaction. Phys. Chem. Chem. Phys. 2014, 16, 1824-1834.

37. Schoeller, W. W.; Rozhenko, A. Pentacoordination at Fluoro-Substituted Silanes by Weak Lewis Donor Addition. Eur. J. Inorg. Chem 2000, 2000, 375-381.

38. Alkorta, I.; Rozas, I.; Elguero, J. Molecular Complexes between Silicon Derivatives and Electron-Rich Groups. J. Phys. Chem. A 2001, 105, 743-749.

39. Scheiner, S. Systematic Elucidation of Factors That Influence the Strength of Tetrel Bonds. J. Phys. Chem. A 2017, 121, 5561-5568.

40. Marín-Luna, M.; Alkorta, I.; Elguero, J. A Theoretical Study of the $\mathrm{H}_{\mathrm{n}} \mathrm{f}_{4-\mathrm{N}} \mathrm{Si}$ :N-Base $(\mathrm{n}=1-4)$ TetrelBonded Complexes. Theor. Chem. Acc. 2017, 136, 41-.

41. Scheiner, S. Comparison of $\mathrm{CH}^{\cdots} \mathrm{O}, \mathrm{SH} \cdots \mathrm{O}$, Chalcogen, and Tetrel Bonds Formed by Neutral and Cationic Sulfur-Containing Compounds. J. Phys. Chem. A 2015, 119, 9189-9199.

42. Liu, M.; Li, Q.; Scheiner, S. Comparison of Tetrel Bonds in Neutral and Protonated Complexes of Pyridinetf $_{3}$ and Furantf $\left(\mathrm{T}=\mathrm{C}, \mathrm{Si}\right.$, and Ge) with $\mathrm{NH}_{3}$. Phys. Chem. Chem. Phys. 2017, 19, 5550-5559.

43. Del Bene, J. E.; Alkorta, I.; Elguero, J. Anionic Complexes of $\mathrm{F}^{-}$and $\mathrm{Cl}^{-}$with Substituted Methanes: Hydrogen, Halogen, and Tetrel Bonds. Chem. Phys. Lett. 2016, 655-656, 115-119.

44. Vojinović, K.; McLachlan, L. J.; Hinchley, S. L.; Rankin, D. W. H.; Mitzel, N. W. Strong Intramolecular Secondary Si'*N Bonds in Trifluorosilylhydrazines. Chem. Eur. J. 2004, 10, 3033-3042. 
45. Hagemann, M.; Berger, R. J. F.; Hayes, S. A.; Stammler, H.-G.; Mitzel, N. W. N,N-

Dimethylaminopropylsilane: A Case Study on the Nature of Weak Intramolecular Si $\cdots \mathrm{N}$ Interactions.

Chem. Eur. J. 2008, 14, 11027-11038.

46. Yamamura, M.; Kano, N.; Kawashima, T.; Matsumoto, T.; Harada, J.; Ogawa, K. Crucial Role of N $\cdots$ Si Interactions in the Solid-State Coloration of Disilylazobenzenes. J. Org. Chem. 2008, 73, 8244-8249.

47. Marín-Luna, M.; Alkorta, I.; Elguero, J. Theoretical Study of the Geometrical, Energetic and NMR Properties of Atranes. J. Organomet. Chem. 2015, 794, 206-215.

48. Korlyukov, A. A.; Lyssenko, K. A.; Antipin, M. Y.; Kirin, V. N.; Chernyshev, E. A.; Knyazev, S. P. Experimental and Theoretical Study of the Transannular Intramolecular Interaction and Cage Effect in the Atrane Framework of Boratrane and 1-Methylsilatrane. Inorg. Chem. 2002, 41, 5043-5051.

49. Mani, D.; Arunan, E. The $\mathrm{X}-\mathrm{CY}(\mathrm{X}=\mathrm{O} / \mathrm{F}, \mathrm{Y}=\mathrm{O} / \mathrm{S} / \mathrm{F} / \mathrm{Cl} / \mathrm{Br} / \mathrm{N} / \mathrm{P})$ 'Carbon Bond' and Hydrophobic Interactions. Phys. Chem. Chem. Phys. 2013, 15, 14377-14383.

50. Li, Q.; Guo, X.; Yang, X.; Li, W.; Cheng, J.; Li, H.-B. A $\sigma$-Hole Interaction with Radical Species as Electron Donors: Does Single-Electron Tetrel Bonding Exist? Phys. Chem. Chem. Phys. 2014, 16, $11617-11625$.

51. Esrafili, M. D.; Mohammadian-Sabet, F. Theoretical Insights into Nature of П-Hole Interactions between Triel Centers (B and Al) and Radical Methyl as a Potential Electron Donor: Do Single-Electron Triel Bonds Exist? Struct. Chem. 2016, 27, 1157-1164.

52. Bauza, A.; Mooibroek, T. J.; Frontera, A. Non-Covalent $\mathrm{sp}^{3}$ Carbon Bonding with ArCF 3 Is Analogous to CH- $\pi$ Interactions. Chem. Commun. 2014, 50, 12626-12629.

53. Liu, M.; Li, Q.; Cheng, J.; Li, W.; Li, H.-B. Tetrel Bond of Pseudohalide Anions with XH3F (X $=$ C, Si, Ge, and Sn) and Its Role in Sn2 Reaction. J. Chem. Phys. 2016, 145, 224310.

54. Del Bene, J. E.; Alkorta, I.; Elguero, J. Carbenes as Electron-Pair Donors to $\mathrm{CO}_{2}$ for $\mathrm{C} \cdots \mathrm{C}$ Tetrel Bonds and C-C Covalent Bonds. J. Phys. Chem. A 2017, 121, 4039-4047.

55. Del Bene, J. E.; Alkorta, I.; Elguero, J. Carbon-Carbon Bonding between Nitrogen Heterocyclic Carbenes and $\mathrm{CO}_{2}$. J. Phys. Chem. A 2017, 121, 8136-8146.

56. Mani, D.; Arunan, E. The $\mathrm{X}-\mathrm{C} \cdots \pi(\mathrm{X}=\mathrm{F}, \mathrm{Cl}, \mathrm{Br}, \mathrm{CN})$ Carbon Bond. J. Phys. Chem. A 2014, 118, 10081-10089.

57. Bauzá, A.; Ramis, R.; Frontera, A. Computational Study of Anion Recognition Based on Tetrel and Hydrogen Bonding Interaction by Calix[4]Pyrrole Derivatives. Comput. Theor. Chem. 2014, 1038, $67-$ 70 .

58. Wei, Y.-X.; Li, H.-B.; Cheng, J.-B.; Li, W.-Z.; Li, Q.-Z. Prominent Enhancing Effects of Substituents on the Strength of $\Pi \cdots \Sigma$-Hole Tetrel Bond. Int. J. Quantum Chem. 2017, 117, e25448.

59. Mikosch, J.; Trippel, S.; Eichhorn, C.; Otto, R.; Lourderaj, U.; Zhang, J. X.; Hase, W. L.; Weidemüller, M.; Wester, R. Imaging Nucleophilic Substitution Dynamics. Science 2008, 319, 183-186.

60. McDowell, S. A. C. Sigma-Hole Cooperativity in Anionic [FX" $\left.\mathrm{CH}_{3} \cdot \mathrm{YF}\right]^{-}(\mathrm{X}, \mathrm{Y}=\mathrm{Cl}, \mathrm{Br})$ Complexes. Chem. Phys. Lett. 2014, 598, 1-4.

61. García-Llinás, X.; Bauzá, A.; Seth, S. K.; Frontera, A. Importance of R-CF 3 - O Tetrel Bonding Interactions in Biological Systems. J. Phys. Chem. A 2017, 121, 5371-5376.

62. Servati Gargari, M.; Stilinović, V.; Bauzá, A.; Frontera, A.; McArdle, P.; Van Derveer, D.; Ng, S. W.; Mahmoudi, G. Design of Lead(II) Metal-Organic Frameworks Based on Covalent and Tetrel Bonding. Chem. Eur. J. 2015, 21, 17951-17958.

63. Mahmoudi, G.; Bauza, A.; Frontera, A.; Garczarek, P.; Stilinovic, V.; Kirillov, A. M.; Kennedy, A.; Ruiz-Perez, C. Metal-Organic and Supramolecular Lead(Ii) Networks Assembled from Isomeric Nicotinoylhydrazone Blocks: The Effects of Ligand Geometry and Counter-Ion on Topology and Supramolecular Assembly. CrystEngComm 2016, 18, 5375-5385.

64. Azofra, L. M.; Scheiner, S. Tetrel, Chalcogen, and $\mathrm{CH} \cdot \mathrm{O}$ Hydrogen Bonds in Complexes Pairing Carbonyl-Containing Molecules with 1, 2, and 3 Molecules of $\mathrm{CO}_{2}$. J. Chem. Phys. 2015, 142, 034307. 
65. Nziko, V. d. P. N.; Scheiner, S. Comparison of $\pi$-Hole Tetrel Bonding with $\sigma$-Hole Halogen Bonds in Complexes of XCN (X = F, Cl, Br, I) and $\mathrm{NH}_{3}$. Phys. Chem. Chem. Phys. 2016, 18, 3581-3590.

66. Guo, X.; Liu, Y.-W.; Li, Q.-Z.; Li, W.-Z.; Cheng, J.-B. Competition and Cooperativity between Tetrel Bond and Chalcogen Bond in Complexes Involving $\mathrm{F}_{2} \mathrm{CX}(\mathrm{X}=\mathrm{Se}$ and $\mathrm{Te})$. Chem. Phys. Lett. 2015, 620, 7-12.

67. Li, Q.-Z.; Zhuo, H.-Y.; Li, H.-B.; Liu, Z.-B.; Li, W.-Z.; Cheng, J.-B. Tetrel-Hydride Interaction between $\mathrm{XH}_{3} \mathrm{~F}(\mathrm{X}=\mathrm{C}, \mathrm{Si}, \mathrm{Ge}, \mathrm{Sn})$ and $\mathrm{HM}(\mathrm{M}=\mathrm{Li}, \mathrm{Na}, \mathrm{BeH}, \mathrm{MgH})$. J. Phys. Chem. A 2015, 119, 2217-2224.

68. Esrafili, M. D.; Mohammadian-Sabet, F. Cooperativity of Tetrel Bonds Tuned by Substituent Effects. Mol. Phys. 2016, 114, 1528-1538.

69. Liu, M.; Li, Q.; Li, W.; Cheng, J. Tetrel Bonds between PySiX3 and Some Nitrogenated Bases: Hybridization, Substitution, and Cooperativity. Journal of Molecular Graphics and Modelling 2016, 65, 35-42.

70. Bauzá, A.; Mooibroek, T. J.; Frontera, A. Tetrel Bonding Interactions. The Chemical Record 2016, 16, 473-487.

71. Esrafili, M. D.; Mohammadirad, N.; Solimannejad, M. Tetrel Bond Cooperativity in Open-Chain $\left(\mathrm{CH}_{3} \mathrm{CN}\right)_{\mathrm{n}}$ and $\left(\mathrm{CH}_{3} \mathrm{NC}\right)_{n}$ Clusters (n=2-7): An Ab Initio Study. Chem. Phys. Lett. 2015, 628, 16-20.

72. Marín-Luna, M.; Alkorta, I.; Elguero, J. Cooperativity in Tetrel Bonds. J. Phys. Chem. A 2016, 120, 648656.

73. Scheiner, S. Highly Selective Halide Receptors Based on Chalcogen, Pnicogen, and Tetrel Bonds. Chem. Eur. J. 2016, 22, 18850-18858.

74. Scheiner, S. Assembly of Effective Halide Receptors from Components. Comparing Hydrogen, Halogen, and Tetrel Bonds. J. Phys. Chem. A 2017, 121, 3606-3615.

75. Scheiner, S. Comparison of Halide Receptors Based on H, Halogen, Chalcogen, Pnicogen, and Tetrel Bonds. Faraday Discussions 2017, 203, 213-226.

76. Frisch, M. J.; Trucks, G. W.; Schlegel, H. B.; Scuseria, G. E.; Robb, M. A.; Cheeseman, J. R.; Scalmani, G.; Barone, V.; Mennucci, B.; Petersson, G. A., et al. Gaussian 09, Revision B.01; Wallingford, CT, 2009.

77. Feller, D. The Role of Databases in Support of Computational Chemistry Calculations. J. Comput. Chem. 1996, 17, 1571-1586.

78. Schuchardt, K. L.; Didier, B. T.; Elsethagen, T.; Sun, L.; Gurumoorthi, V.; Chase, J.; Li, J.; Windus, T. L. Basis Set Exchange: A Community Database for Computational Sciences. J. Chem. Infor. Model. 2007, 47, 1045-1052.

79. Spada, L.; Gou, Q.; Geboes, Y.; Herrebout, W. A.; Melandri, S.; Caminati, W. Rotational Study of Dimethyl Ether-Chlorotrifluoroethylene: Lone Pair $\cdots \Pi$ Interaction Links the Two Subunits. J. Phys. Chem. A 2016, 120, 4939-4943.

80. Shukla, R.; Chopra, D. "Pnicogen Bonds" or "Chalcogen Bonds": Exploiting the Effect of Substitution on the Formation of P...Se Noncovalent Bonds. Phys. Chem. Chem. Phys. 2016, 18, 13820-13829.

81. Tang, Q.; Li, Q. Non-Additivity of F Substituent in Enhancing the Halogen Bond in $\mathrm{C}_{6} \mathrm{H}_{5} \mathrm{I} \cdots \mathrm{NCH}$. Comput. Theor. Chem. 2015, 1070, 21-26.

82. Geboes, Y.; Proft, F. D.; Herrebout, W. A. Expanding Lone Pair $\cdots \Pi$ Interactions to Nonaromatic Systems and Nitrogen Bases: Complexes of $\mathrm{C}_{2} \mathrm{~F}_{3} \mathrm{X}(\mathrm{X}=\mathrm{F}, \mathrm{Cl}, \mathrm{Br}, \mathrm{I})$ and TMA-D9. J. Phys. Chem. A 2015, 119, 5597-5606.

83. Sutradhar, D.; Chandra, A. K.; Zeegers-Huyskens, T. A Theoretical Investigation of the Interaction between Fluorinated Dimethyl Ethers and Molecular Chlorine. Mol. Phys. 2014, 112, 2791-2801.

84. Sanchez-Sanz, G.; Trujillo, C.; Alkorta, I.; Elguero, J. Intramolecular Pnicogen Interactions in Phosphorus and Arsenic Analogues of Proton Sponges. Phys. Chem. Chem. Phys. 2014, 16, 1590015909.

85. Esrafili, M. D.; Fatehi, P.; Solimannejad, M. Mutual Interplay between Pnicogen Bond and Dihydrogen Bond in $\mathrm{HMH} \cdots \mathrm{HCN} \cdots \mathrm{PH}_{2} \mathrm{X}$ Complexes $(\mathrm{M}=\mathrm{Be}, \mathrm{Mg}, \mathrm{Zn} ; \mathrm{X}=\mathrm{H}, \mathrm{F}, \mathrm{Cl})$. Comput. Theor. Chem. 2014, $1034,1-6$. 
86. Hauchecorne, D; Herrebout, W. A. Experimental Characterization of $\mathrm{C}-\mathrm{X} \cdots \mathrm{Y}-\mathrm{C}(\mathrm{X}=\mathrm{Br}, \mathrm{I} ; \mathrm{Y}=\mathrm{F}, \mathrm{Cl})$ Halogen-Halogen Bonds. J. Phys. Chem. A 2013, 117, 11548-11557.

87. Liu, X.; Cheng, J.; Li, Q.; Li, W. Competition of Hydrogen, Halogen, and Pnicogen Bonds in the Complexes of $\mathrm{HArF}$ with $\mathrm{XH}_{2} \mathrm{P}(\mathrm{X}=\mathrm{F}, \mathrm{Cl}$, and $\mathrm{Br})$. Spectrochim. Acta A 2013, 101, 172-177.

88. Boys, S. F.; Bernardi, F. The Calculation of Small Molecular Interactions by the Differences of Separate Total Energies. Some Procedures with Reduced Errors. Mol. Phys. 1970, 19, 553-566.

89. Zhurko, G. A. Chemcraft, 1.8; http://www.Chemcraftprog.Com. accessed 14 May, 2016

90. Lu, T.; Chen, F. Multiwfn: A Multifunctional Wavefunction Analyzer. J. Comput. Chem. 2012, 33, 580592.

91. Glendening, E. D.; Landis, C. R.; Weinhold, F. NBO 6.0: Natural Bond Orbital Analysis Program. $J$. Comput. Chem. 2013, 34, 1429-1437.

92. Bader, R. F. W.; Carroll, M. T.; Cheeseman, J. R.; Chang, C. Properties of Atoms in Molecules: Atomic Volumes. J. Am. Chem. Soc. 1987, 109, 7968-7979.

93. Bader, R. F. W. Atoms in Molecules, A Quantum Theory. Clarendon Press: Oxford, 1990; Vol. 22 , p 438.

94. Keith, T. A. Aimall, TK Gristmill Software: Overland Park KS, 2013.

95. Parthasarathi, R.; Subramanian, V.; Sathyamurthy, N. Hydrogen Bonding without Borders: An Atoms-inMolecules Perspective. J. Phys. Chem. A 2006, 110, 3349-3351.

96. Grabowski, S. J. A New Measure of Hydrogen Bonding Strength - Ab Initio and Atoms in Molecules Studies. Chem. Phys. Lett. 2001, 338, 361-366.

97. Scheiner, S. Halogen Bonds Formed between Substituted Imidazoliums and N Bases of Varying NHybridization. Molecules 2017, 22, 1634.

98. Ebrahimi, A.; Khorassani, M. H.; Delarami, H. Estimation of Individual Binding Energies in Some Dimers Involving Multiple Hydrogen Bonds Using Topological Properties of Electron Charge Density. Chem. Phys. 2009, 365, 18-23.

99. Biswal, H. S. Hydrogen Bonds Involving Sulfur: New Insights from Ab Initio Calculations and Gas Phase Laser Spectroscopy. In Noncovalent Forces, Scheiner, S., Ed. Springer: Dordrecht, Netherlands, 2015; Vol. 19, pp 15-45.

100. Grabowski, S. J.; Sokalski, W. A. Are Various $\Sigma$-Hole Bonds Steered by the Same Mechanisms? ChemPhysChem. 2017, 18, 1569-1577.

101. Nziko, V. d. P. N.; Scheiner, S. Catalysis of the Aza-Diels-Alder Reaction by Hydrogen and Halogen Bonds. J. Org. Chem. 2016, 81, 2589-2597.

102. Bauzá, A.; Frontera, A. On the Importance of П-Hole Beryllium Bonds: Theoretical Study and Biological Implications. Chem. Eur. J. 2017, 23, 5375-5380.

103. Bauza, A.; Frontera, A. Theoretical Study on $\sigma$ - and $\pi$-Hole Carbon $\cdots$ Carbon Bonding Interactions: Implications in Cfc Chemistry. Phys. Chem. Chem. Phys. 2016, 18, 32155-32159.

104. Marín-Luna, M.; Alkorta, I.; Elguero, J. The Effect of Cytosine Methylation on Its Halogen-Bonding Properties. Comput. Theor. Chem. 2016, 1076, 101-108.

105. Del Bene, J. E.; Alkorta, I.; Elguero, J. Can $\mathrm{HN}=\mathrm{NH}$, $\mathrm{FN}=\mathrm{NH}$, or $\mathrm{HN}=\mathrm{CHOH}$ Bridge the $\sigma$-Hole and the Lone Pair at $\mathrm{P}$ in Binary Complexes with $\mathrm{H}_{2} \mathrm{XP}$, for $\mathrm{X}=\mathrm{F}, \mathrm{Cl}, \mathrm{NC}, \mathrm{OH}, \mathrm{CN}, \mathrm{CCH}, \mathrm{CH}_{3}$, and $\mathrm{H}$ ? Phys. Chem. Chem. Phys. 2015, 17, 30729-30735.

106. Nziko, V. d. P. N.; Scheiner, S. Interactions between Thiourea and Imines. Prelude to Catalysis. J. Org. Chem. 2015, 80, 10334-10341.

107. Munusamy, E.; Sedlak, R.; Hobza, P. On the Nature of the Stabilization of Benzene $\cdots$ Dihalogen and Benzene'-Dinitrogen Complexes: CCSD(T)/CBS and DFT-SAPT Calculations. ChemPhysChem. 2011, 12, 3253-3261.

108. Azofra, L. M.; Alkorta, I.; Scheiner, S. Strongly Bound Noncovalent $\left(\mathrm{SO}_{3}\right)_{\mathrm{n}}: \mathrm{H}_{2} \mathrm{CO}$ Complexes $(\mathrm{n}=1,2)$. Phys. Chem. Chem. Phys. 2014, 16, 18974-18981.

109. Scheiner, S. Detailed Comparison of the Pnicogen Bond with Chalcogen, Halogen and Hydrogen Bonds. Int. J. Quantum Chem. 2013, 113, 1609-1620. 
110. Scheiner, S. Extrapolation to the Complete Basis Set Limit for Binding Energies of Noncovalent Interactions. Comput. Theor. Chem. 2012, 998, 9-13.

111. Scheiner, S. Effects of Substituents Upon the P*-N Noncovalent Interaction: The Limits of Its Strength. $J$. Phys. Chem. A 2011, 115, 11202-11209.

112. Fanfrlík, J.; Zierkiewicz, W.; Švec, P.; Růžičková, Z.; Řezáč, J.; Michalczyk, M.; Růžička, A.; Michalska, D.; Hobza, P. Pnictogen Bonding in Pyrazine $P n X 5(\mathrm{Pn}=\mathrm{P}, \mathrm{As}, \mathrm{Sb}$ and X = F, Cl, Br) Complexes. J. Mol. Model. 2017, 23, 328.

113. Matczak, P. Theoretical Investigation of the $\mathrm{N} \rightarrow$ sn Coordination in $\left(\mathrm{Me}_{3} \mathrm{SnCN}\right)_{2}$. Struct. Chem. 2015, 26, 301-318.

114. Grabowski, S. J. Tetrel Bonds, Penta- and Hexa-Coordinated Tin and Lead Centres. Applied Organometallic Chemistry 2017, e3727.

115. Politzer, P.; Murray, J.; Clark, T. Mathematical Modeling and Physical Reality in Noncovalent Interactions. J. Mol. Model. 2015, 21, 52-61.

116. Clark, T.; Politzer, P.; Murray, J. S. Correct Electrostatic Treatment of Noncovalent Interactions: The Importance of Polarization. WIRE: Comput. Mol. Sci. 2015, 5, 169-177.

117. Politzer, P.; Murray, J. S.; Clark, T. $\Sigma$-Hole Bonding: A Physical Interpretation. Top. Curr. Chem. 2015, 358, 19-42.

118. Thirman, J.; Engelage, E.; Huber, S. M.; Head-Gordon, M. Characterizing the Interplay of Pauli Repulsion, Electrostatics, Dispersion and Charge Transfer in Halogen Bonding with Energy Decomposition Analysis. Phys. Chem. Chem. Phys. 2018, 20, 905-915.

119. Sedlak, R.; Eyrilmez, S. M.; Hobza, P.; Nachtigallova, D. The Role of the $\sigma$-Holes in Stability of NonBonded Chalcogenide -'Benzene Interactions: The Ground and Excited States. Phys. Chem. Chem. Phys. 2018, 20, 299-306.

120. Buralli, G. J.; Duarte, D. J. R.; Peruchena, N. M.; Alkorta, I. Simultaneous Occurrence of Quadruple Lewis Acid-Base Interactions between Selenium Atoms in Selenocarbonyl Dimers. ChemPhysChem. 2017, 18, 3498-3503.

121. Stone, A. J. Natural Bond Orbitals and the Nature of the Hydrogen Bond. J. Phys. Chem. A 2017, 121, 1531-1534.

122. Riley, K. E.; Vazquez, M.; Umemura, C.; Miller, C.; Tran, K.-A. Exploring the (Very Flat) Potential Energy Landscape of $\mathrm{R}-\mathrm{Br} \cdots \Pi$ Interactions with Accurate CCSD(T) and SAPT Techniques. Chem. Eur. J. 2016, 22, 17690-17695.

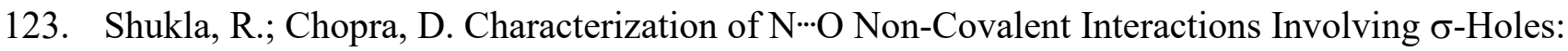
"Electrostatics" or "Dispersion". Phys. Chem. Chem. Phys. 2016, 18, 29946-29954.

124. Horn, P. R.; Mao, Y.; Head-Gordon, M. Probing Non-Covalent Interactions with a Second Generation Energy Decomposition Analysis Using Absolutely Localized Molecular Orbitals. Phys. Chem. Chem. Phys. 2016, 18, 23067-23079. 
Table 1. Equilibrium $\mathrm{R}(\mathrm{Si} \cdot \mathrm{N})$ intermolecular distance in complexes of $\mathrm{FSiR}_{3}$ with $\mathrm{NH}_{3}$. Interaction energies of dimers, and deformation energies induced in monomers in order to form dimer. Energies in $\mathrm{kcal} / \mathrm{mol}$.

\begin{tabular}{|l|l|l|l|l|l|}
\hline $\mathrm{FSiR}_{3}$ & \multicolumn{1}{|c|}{$\mathrm{R}, \AA$} & \multicolumn{1}{c|}{$\mathrm{A}$} & \multicolumn{1}{c|}{$\mathrm{E}_{\text {def }}(\mathrm{LA})$} & \multicolumn{1}{c|}{$\mathrm{E}_{\text {def }}(\mathrm{LB})$} & $\mathrm{E}_{\text {int }}=\Delta \mathrm{E}-\mathrm{E}_{\text {def }}$ \\
\hline $\mathrm{FSiH}_{3}$ & 2.557 & -5.49 & 1.93 & 0.00 & -7.42 \\
\hline $\mathrm{FSiMe}_{3}{ }^{\mathrm{a}}$ & 3.753 & -2.24 & 0.12 & 0.01 & -2.37 \\
\hline $\mathrm{FSiMe}_{2}\left(\mathrm{CF}_{3}\right)_{1}$ & 2.392 & -2.11 & 11.02 & 0.02 & -13.15 \\
\hline $\mathrm{FSiMe}_{1}\left(\mathrm{CF}_{3}\right)_{2}$ & 2.208 & -9.22 & 15.70 & 0.05 & -24.97 \\
\hline $\mathrm{FSi}_{\left(\mathrm{CF}_{3}\right)_{3}}$ & 2.116 & -18.20 & 17.29 & 0.06 & -35.55 \\
\hline $\mathrm{FSiIsO}_{3} \mathrm{a}$ & 3.091 & +0.24 & 2.48 & 0.02 & -2.26 \\
\multicolumn{1}{c}{$\mathrm{b}$} & 2.499 & +6.80 & 14.16 & 0.00 & -7.36 \\
\hline $\mathrm{FSiIsO}_{2}\left(\mathrm{CF}_{3}\right)_{1}$ & 2.384 & -2.70 & 10.26 & 0.02 & -12.98 \\
\hline $\mathrm{FSiTb}_{3}$ & 2.519 & +10.80 & 17.41 & 0.00 & -6.61 \\
\hline $\mathrm{FSiCl}_{3}$ & 2.068 & -5.45 & 19.73 & 0.16 & -25.34 \\
\hline $\mathrm{FSiBr}_{3}$ & 2.078 & -4.73 & 17.70 & 0.19 & -22.61 \\
\hline $\mathrm{FSiI}_{3}$ & 2.130 & -3.31 & 14.57 & 0.21 & -18.09 \\
\hline
\end{tabular}

${ }^{a}$ primarily stabilized by $\mathrm{CH} \cdot \mathrm{N}$ 
Table 2. Maximum electrostatic potential on isodensity surface of $\mathrm{FSiR}_{3}$, density at $\mathrm{Si} \cdot \mathrm{N}$ bond critical point and NBO charge transfer energy from $\mathrm{N}$ lone pair (or SiN bonding orbital) to indicated antibonding orbital in Lewis acid.

\begin{tabular}{|c|c|c|c|c|c|}
\hline $\mathrm{FSiR}_{3}$ & $\begin{array}{l}\mathrm{V}_{\mathrm{s}, \max } \\
\mathrm{kcal} / \mathrm{mol}\end{array}$ & $\begin{array}{c}\mathrm{R}\left(\mathrm{Si} \cdot \mathrm{V}_{\mathrm{s}, \max }\right) \\
\AA\end{array}$ & $\begin{array}{c}\rho_{\mathrm{BCP}} \\
\mathrm{au}\end{array}$ & $\begin{array}{l}\text { NBO E(2) } \\
\mathrm{kcal} / \mathrm{mol}\end{array}$ & $\begin{array}{c}\Delta \mathrm{r}(\mathrm{Si}-\mathrm{F}) \\
\AA\end{array}$ \\
\hline $\mathrm{FSiH}_{3}$ & 41.016 & 1.940 & 0.0233 & $\begin{array}{l}17.97(\mathrm{Si}-\mathrm{F}) \\
3.90(3 \mathrm{Si}-\mathrm{H})\end{array}$ & 0.026 \\
\hline $\mathrm{FSiMe}_{3}$ & 26.919 & 2.134 & $0.0056\left(3 \mathrm{H}^{\mathrm{a}}\right)$ & $\begin{array}{l}1.30(\mathrm{Si}-\mathrm{F}) \\
0.57(3 \mathrm{C}-\mathrm{H})\end{array}$ & 0.005 \\
\hline $\mathrm{FSiMe}_{2}\left(\mathrm{CF}_{3}\right)_{1}$ & 31.713 & 2.178 & $\begin{array}{l}0.0325 \\
0.0121\left(1 \mathrm{~F}^{\mathrm{b}}\right)\end{array}$ & $\begin{array}{l}18.31(\mathrm{Si}-\mathrm{F}) \\
11.10\left(\mathrm{Si}-\mathrm{CF}_{3}\right) \\
7.43\left(2 \mathrm{Si}-\mathrm{CH}_{3}\right) \\
2.19(\mathrm{C}-\mathrm{F})\end{array}$ & 0.036 \\
\hline $\mathrm{FSiMe}_{1}\left(\mathrm{CF}_{3}\right)_{2}$ & 35.005 & 2.235 & 0.0455 & $\begin{array}{l}21.24(\mathrm{Si}-\mathrm{F}) \\
14.73\left(2 \mathrm{Si}-\mathrm{CF}_{3}\right) \\
8.93\left(\mathrm{Si}-\mathrm{CH}_{3}\right) \\
2.41(2 \mathrm{C}-\mathrm{F})\end{array}$ & 0.041 \\
\hline $\mathrm{FSi}\left(\mathrm{CF}_{3}\right)_{3}$ & 42.369 & 2.198 & 0.0551 & $\begin{array}{l}26.66(\mathrm{Si}-\mathrm{F}) \\
18.75\left(3 \mathrm{Si}^{-} \mathrm{CF}_{3}\right) \\
2.29(2 \mathrm{C}-\mathrm{F})\end{array}$ & 0.042 \\
\hline $\mathrm{FSiIsO}_{3}{ }^{\mathrm{d}}$ & $\begin{array}{ll}\text { a } & 21.994 \\
\text { b } & 9.917\end{array}$ & $\begin{array}{l}\text { a } 2.241 \\
\text { b } 3.016\end{array}$ & $\begin{array}{l}0.0095\left(3 \mathrm{H}^{\mathrm{a}}\right) \\
0.0096\left(1 \mathrm{C}^{\mathrm{c}}\right)\end{array}$ & $\begin{array}{l}8.25(\mathrm{Si}-\mathrm{F}) \\
1.46(3 \mathrm{Si}-\mathrm{C})\end{array}$ & 0.011 \\
\hline $\mathrm{FSiIsO}_{2}\left(\mathrm{CF}_{3}\right)_{1}$ & 23.073 & 2.268 & 0.0332 & $\begin{array}{l}19.67(\mathrm{Si}-\mathrm{F}) \\
11.82\left(\mathrm{Si}_{-} \mathrm{CF}_{3}\right) \\
8.81\left(2 \mathrm{Si}-\mathrm{C}_{\text {iso }}\right) \\
\end{array}$ & 0.036 \\
\hline $\mathrm{FSiTb}_{3}$ & 11.140 & 3.217 & 0.0264 & $\begin{array}{l}23.56(\mathrm{Si}-\mathrm{F}) \\
8.13(3 \mathrm{Si}-\mathrm{C}) \\
\end{array}$ & 0.037 \\
\hline $\mathrm{FSiCl}_{3}$ & 27.019 & 2.167 & 0.0605 & $\begin{array}{l}\text { 19.72(Si-F) } \\
17.05(3 \mathrm{Si}-\mathrm{Cl})\end{array}$ & 0.036 \\
\hline $\mathrm{FSiBr}_{3}$ & 21.359 & 2.260 & 0.0601 & $\begin{array}{l}\text { 20.11(Si-F) } \\
17.30(3 \mathrm{Si}-\mathrm{Br})\end{array}$ & 0.035 \\
\hline $\mathrm{FSiI}_{3}$ & 14.140 & 2.414 & 0.0579 & $\begin{array}{l}18.67(\mathrm{Si}-\mathrm{F}) \\
15.12(3 \mathrm{Si}-\mathrm{I})\end{array}$ & 0.037 \\
\hline
\end{tabular}

abonds involving $\mathrm{N}$ and one $\mathrm{H}$ atom of each alkyl group

bond involving $\mathrm{N}$ and one $\mathrm{F}$ atom of $\mathrm{CF}_{3}$ group

bond involving $\mathrm{N}$ and $\mathrm{C}$ atom of one alkyl group

${ }^{\mathrm{d}} \mathrm{AIM}$ and NBO data for complex a 
Table 3. Equilibrium $\mathrm{R}(\mathrm{T} \cdot \mathrm{N})$ intermolecular distance in complexes of $\mathrm{FTR}_{3}$ with $\mathrm{NH}_{3}, \mathrm{~T}=\mathrm{Ge}, \mathrm{Sn}, \mathrm{Pb}$.

Interaction energies of dimers, and deformation energies induced in monomers in order to form dimer. Energies in $\mathrm{kcal} / \mathrm{mol}$.

\begin{tabular}{|l|l|l|l|l|l|}
\hline $\mathrm{FTR}_{3}$ & \multicolumn{1}{|c|}{$\mathrm{R}, \AA$} & \multicolumn{1}{|c|}{$\Delta \mathrm{E}$} & \multicolumn{1}{|c|}{$\mathrm{E}_{\text {def }}(\mathrm{LA})$} & \multicolumn{1}{c|}{$\mathrm{E}_{\text {def }}(\mathrm{LB})$} & $\mathrm{E}_{\text {int }}=\Delta \mathrm{E}-\mathrm{E}_{\text {def }}$ \\
\hline $\mathrm{FGeH}_{3}$ & 2.627 & -5.84 & 1.49 & 0.00 & -7.33 \\
\hline $\mathrm{FGeMe}_{3}$ & 2.775 & -1.36 & 0.40 & 0.01 & -1.77 \\
\hline $\mathrm{FGeIso}_{3}$ & 2.823 & -3.64 & 2.38 & 0.00 & -6.02 \\
\hline $\mathrm{FGeTb}_{3}$ & 2.670 & +6.63 & 12.71 & 0.00 & -6.08 \\
\hline $\mathrm{FSnTb}_{3}$ & 2.653 & -3.42 & 6.41 & 0.01 & -9.84 \\
\hline $\mathrm{FPbTb}_{3}$ & 2.851 & -4.77 & 2.89 & 0.00 & -7.66 \\
\hline
\end{tabular}

Table 4. Maximum electrostatic potential on isodensity surface of $\mathrm{FTR}_{3}$, density at $\mathrm{T} \cdot \mathrm{N}$ bond critical point and NBO charge transfer energy from $\mathrm{N}$ lone pair to indicated antibonding orbital in Lewis acid..

\begin{tabular}{|c|c|c|c|c|c|}
\hline $\mathrm{FTR}_{3}$ & $\begin{array}{c}\mathrm{V}_{\mathrm{s}, \max } \\
\mathrm{kcal} / \mathrm{mol}\end{array}$ & $\begin{array}{c}\mathrm{R}\left(\mathrm{T}^{\cdot} \cdot \mathrm{V}_{\AA} \mathrm{V}_{\mathrm{s}, \max }\right) \\
\AA\end{array}$ & $\begin{array}{c}\rho_{\mathrm{BCP}} \\
\mathrm{au}\end{array}$ & $\begin{array}{c}\mathrm{NBO} E(2) \\
\mathrm{kcal} / \mathrm{mol}\end{array}$ & $\begin{array}{c}\Delta \mathrm{r}(\mathrm{T}-\mathrm{F}) \\
\AA\end{array}$ \\
\hline $\mathrm{FGeH}_{3}$ & 50.085 & 1.936 & 0.0236 & $\begin{array}{l}17.58(\mathrm{Ge}-\mathrm{F}) \\
3.71(3 \mathrm{Ge}-\mathrm{H})\end{array}$ & 0.031 \\
\hline $\mathrm{FGeMe}_{3}$ & 30.551 & 2.116 & 0.0179 & $\begin{array}{l}14.04(\mathrm{Ge}-\mathrm{F}) \\
2.95(3 \mathrm{Ge}-\mathrm{C})\end{array}$ & 0.026 \\
\hline $\mathrm{FGeIsO}_{3}$ & 28.374 & 2.112 & 0.0166 & $\begin{array}{l}16.16(\mathrm{Ge}-\mathrm{F}) \\
3.34(3 \mathrm{Ge}-\mathrm{C})\end{array}$ & 0.022 \\
\hline $\mathrm{FGeTb}_{3}$ & 13.892 & 3.035 & $\begin{array}{l}0.0288 \\
0.0092(\mathrm{C}) \\
0.0134(2 \mathrm{H}) \\
0.0052(\mathrm{H})\end{array}$ & $\begin{array}{l}21.39(\mathrm{Ge}-\mathrm{F}) \\
6.13(3 \mathrm{Ge}-\mathrm{C})\end{array}$ & 0.039 \\
\hline $\mathrm{FSnTb}_{3}$ & 35.767 & 2.291 & $\begin{array}{l}0.0291 \\
0.0087 \mathrm{H} \\
0.0094 \mathrm{H}\end{array}$ & $\begin{array}{l}20.94(\mathrm{Sn}-\mathrm{F}) \\
9.85(3 \mathrm{Sn}-\mathrm{C})\end{array}$ & 0.047 \\
\hline $\mathrm{FPbTb}_{3}$ & 45.789 & 2.142 & $\begin{array}{l}0.0229 \\
0.0069 \mathrm{H} \\
0.0087 \mathrm{H} \\
0.0042 \mathrm{H} \\
0.0074 \mathrm{H}\end{array}$ & $\begin{array}{l}19.28(\mathrm{~Pb}-\mathrm{F}) \\
5.52(3 \mathrm{~Pb}-\mathrm{C})\end{array}$ & 0.049 \\
\hline
\end{tabular}

Table 5. Correlation coefficients between pairs of parameters

\begin{tabular}{|l|l|l|}
\hline$p_{1}$ & $p_{2}$ & $R^{2}$ \\
\hline$\Delta r(T-F)$ & $\mathrm{E}(2) \mathrm{N}_{1 p} \rightarrow \sigma^{*}(\mathrm{TF})$ & 0.882 \\
\hline $\mathrm{E}_{\text {int }}$ & $\mathrm{E}(2) \mathrm{N}_{\mathrm{lp}} \rightarrow \sigma^{*}(\mathrm{TF})$ & 0.564 \\
\hline $\mathrm{E}_{\text {int }}$ & $\mathrm{E}(2)$ total & 0.893 \\
\hline $\mathrm{E}_{\text {int }}$ & $\rho_{\text {BCP }}$ & 0.877 \\
\hline $\mathrm{E}_{\text {int }}$ & $\mathrm{R}(\mathrm{T} \cdot \mathrm{N})$ & 0.751 \\
\hline$\Delta \mathrm{E}$ & $\rho_{\mathrm{BCP}}$ & 0.471 \\
\hline$\Delta \mathrm{E}$ & $\mathrm{E}(2)$ total & 0.489 \\
\hline
\end{tabular}


Table 6. Interaction energies ( $\mathrm{kcal} / \mathrm{mol})$ computed at MP2 level with two different basis sets for complexes with $\mathrm{NH}_{3}$

\begin{tabular}{|l|l|l|}
\hline $\mathrm{FTR}_{3}$ & aug-cc-pVDZ & aug-cc-pVTZ \\
\hline $\mathrm{FSiH}_{3}$ & -7.42 & -8.72 \\
\hline $\mathrm{FSiMe}_{3}$ & -2.37 & -2.59 \\
\hline $\mathrm{FSi}_{3}\left(\mathrm{CF}_{3}\right)_{3}$ & -35.55 & -40.20 \\
\hline $\mathrm{FSiCl}_{3}$ & -25.34 & -29.90 \\
\hline $\mathrm{FSiBr}_{3}$ & -22.61 & -27.49 \\
\hline $\mathrm{FSiI}_{3}$ & -18.09 & -23.20 \\
\hline $\mathrm{FGeH}_{3}$ & -7.33 & -8.08 \\
\hline $\mathrm{FGeMe}_{3}$ & -1.77 & -3.40 \\
\hline
\end{tabular}




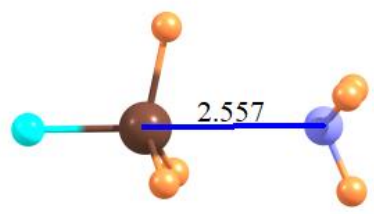

a) $\mathrm{FSiH}_{3}$

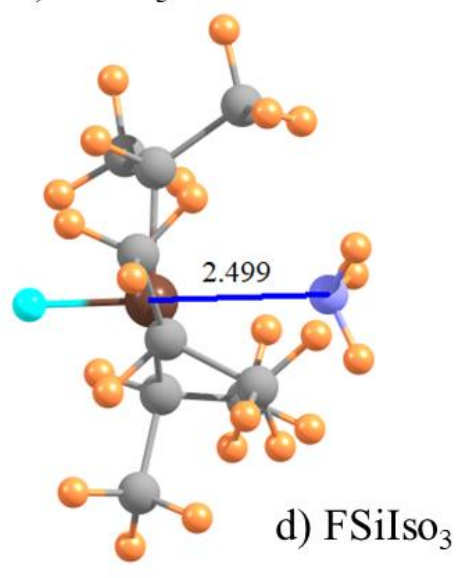

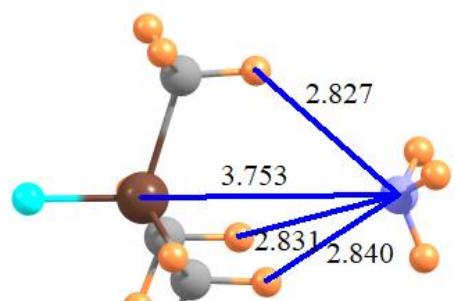

b) $\mathrm{FSiMe}_{3}$

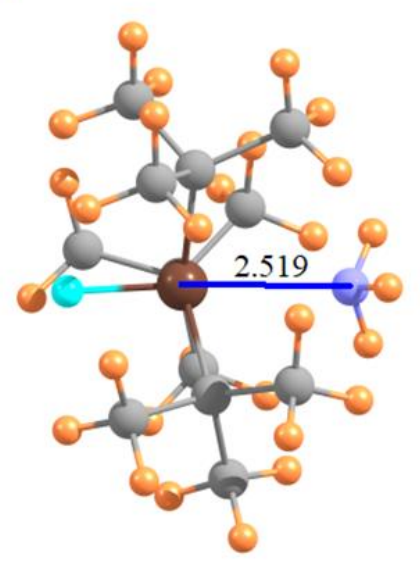

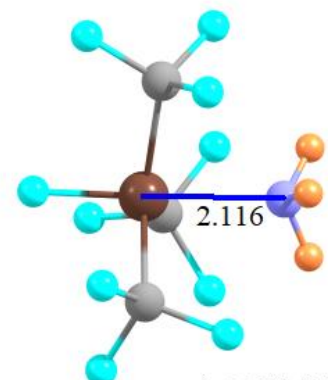

c) $\mathrm{FSi}\left(\mathrm{CF}_{3}\right)_{3}$

Fig 1. Geometries of indicated $\mathrm{FSiR}_{3}$ Lewis acids with $\mathrm{NH}_{3}$. Distances in $\AA$.

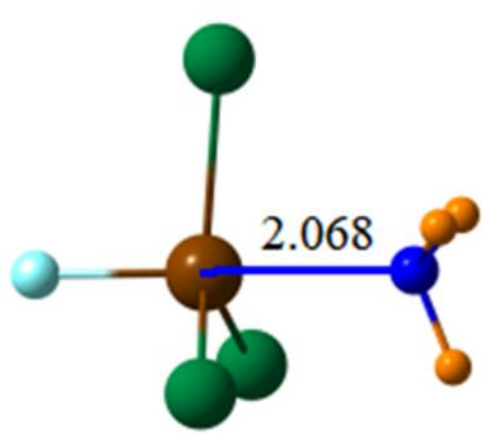

a) $\mathrm{FSiCl}_{3}$

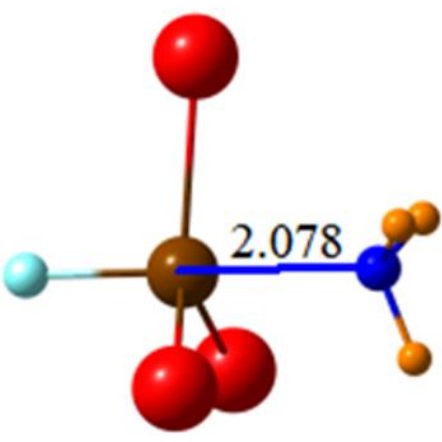

b) $\mathrm{FSiBr}_{3}$

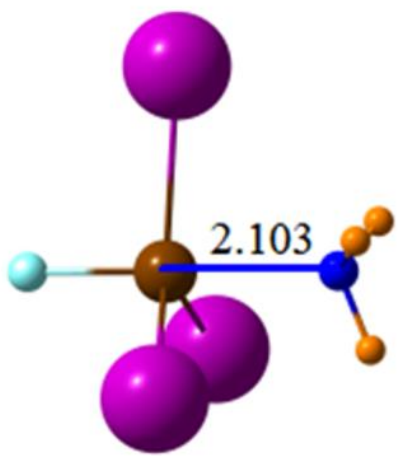

c) $\mathrm{FSiI}_{3}$

Fig 2. Geometries of indicated $\mathrm{FSiX}_{3}$ Lewis acids with $\mathrm{NH}_{3}$. Distances in $\AA$. 


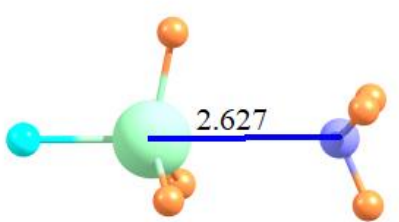

a) $\mathrm{FGeH}_{3}$

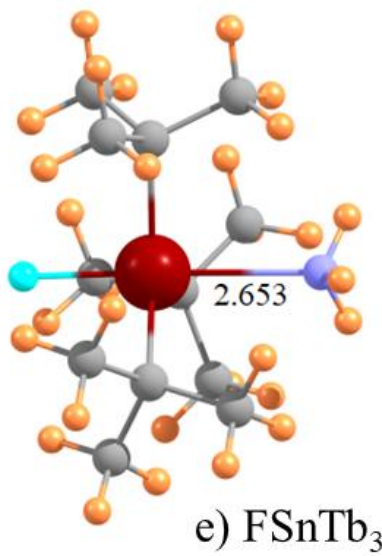

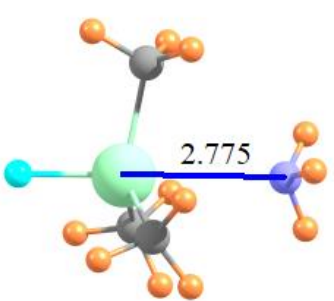

b) $\mathrm{FGeMe}_{3}$

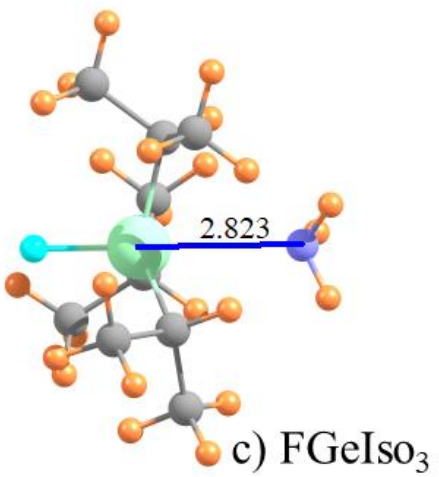

c) $\mathrm{FGeIsO}_{3}$

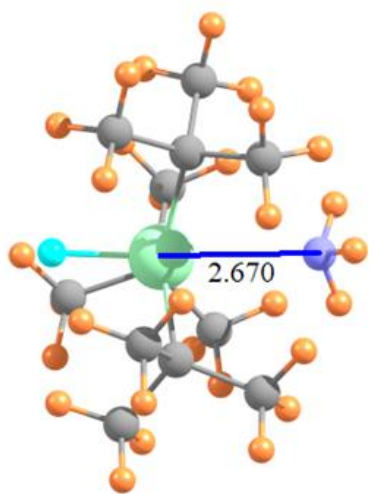

d) $\mathrm{FGeTb}_{3}$

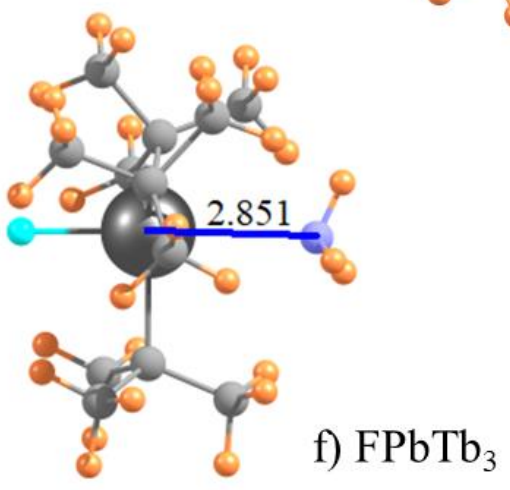

Fig 3. Geometries of indicated $\mathrm{FTR}_{3}$ Lewis acids $(\mathrm{T}=\mathrm{Ge}, \mathrm{Sn}, \mathrm{Pb})$ with $\mathrm{NH}_{3}$. Distances in $\AA$. 
TOC GRAPHIC

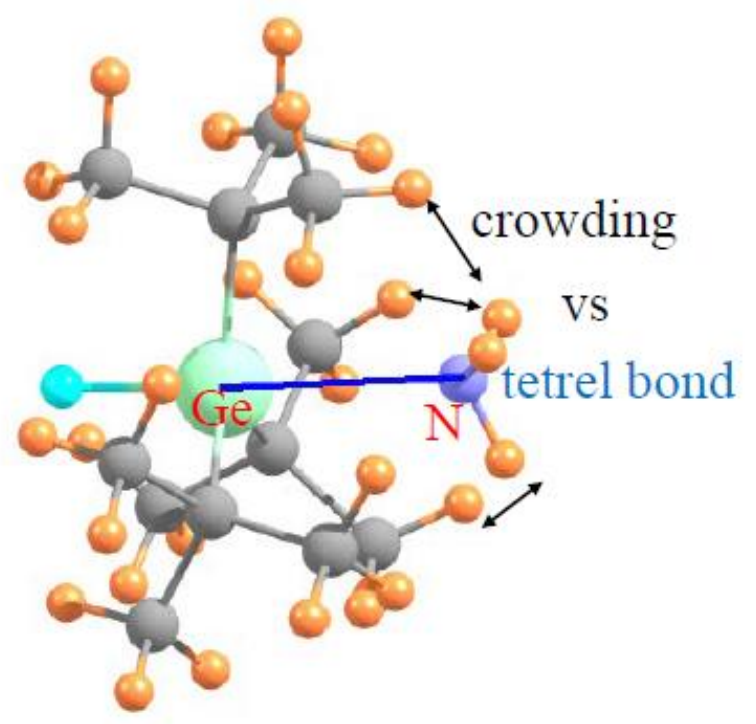

